\title{
A new bat species of the genus Myotis with comments on the phylogenetic placement of M. keaysi and M. pilosatibialis
}

\author{
Carlos Alberto Carrión-Bonilla ${ }^{1,2 *}$, and Joseph Anthony CoOK $^{1}$ \\ ${ }^{1}$ Department of Biology and Museum of Southwestern Biology, University of New Mexico. Albuquerque, NM 87131, USA. \\ Email:ccarrion@unm.edu, lophostoma1@gmail.com (CACB), tucojoe@gmail.com (JAC). \\ ${ }^{2}$ Museo de Zoología. Escuela de Ciencias Biológicas. Pontificia Universidad Católica del Ecuador. Av. 12 de Octubre y Roca, \\ Apartado 17-01-2184. Quito, Ecuador. Email:ccarrion@unm.edu, lophostoma1@gmail (CAC-B). \\ *Corresponding author
}

Molecular studies of Neotropical Myotis (Chiroptera, Vespertilionidae) in the last decade have uncovered substantial cryptic diversity. One example is M. keaysi pilosatibialis, which is characterized by a complex taxonomy derived from low morphological variation. Herein, we studied cryptic diversity of a high elevation clade from premontane and montane forest of Chiriquí Province (Panamá), Cordillera Oriental (Ecuador), and Valle del Silencio (Costa Rica). Additionally, we disentangle relationships of M. k. keaysi and M. k. pilosatibialis by determining their phylogenetic placement within the Neotropical Myotis radiation. In the process, we identified a new lineage of species level hierarchy that is described herein. We used an integrative taxonomy approach, using a combination of linear morphometrics, qualitative morphology, molecular phylogenetics, and climatic analysis. The newly identified lineage is a sister species to M. pilosatibialis str., but differs from M. sp. (Quintana Roo, México), M. keaysi str., and M. oxyotus gardneri in size and other quantitative morphological characters in addition to both nuclear and mitochondrial DNA sequence divergence. Based on our phylogenetic analysis of partial cytochrome $b$ sequence, the polyphyly of $M$. keaysi str. and M. pilosatibialis str. is resolved, with $M$. keaysi str. paraphyletic to $M$. ruber and $M$. simus. Myotis pilosatibialis is part of a monophyletic clade that is sister to the newly identified species. This report refines our understanding of taxonomy and systematics of the Myotis pilosatibialis complex of bats, identifies and describes a new species of Myotis, and more broadly it contributes to efforts to characterize species in this genus in Neotropical environments. Based on its distribution, we classified this newly described species as paramontane due to its restriction to premontane and montane forest of Chiriquí Province (Panamá), Valle del Silencio (Costa Rica), and Cordillera Oriental (Ecuador). These habitats are susceptible to the effects of climate change, in addition to ongoing habitat destruction.

Los estudios de genética molecular del género de murciélagos Neotropicales Myotis (Chiroptera: Vespertilionidae) han permitido descubrir diversidad críptica en la última década. Un ejemplo es $M$. keaysi pilosatibialis, el cual se caracteriza por una taxonomía compleja con poca variabilidad morfológica. En esta investigación, estudiamos un clado de murciélagos myotinos de los bosques premontanos y montanos de la Provincia de Chiriquí (Panamá), Cordillera Oriental (Ecuador) y el Valle del Silencio (Costa Rica). Adicionalmente, resolvemos las relaciones de $M$. k. keaysi y M. k. pilosatibialis al determinar su posición filogenética en la radiación de Myotis en el Neotrópico. En el proceso, identificamos una entidad biológica a nivel de especies que es descrita es esta contribución. Desde un enfoque de taxonomía integrativa, utilizamos una combinación de morfometría lineal, caracteres morfológicos cualitativos, así como análisis filogenéticos moleculares y de clima. La nueva especie es evolutivamente cercana a M. pilosatibialis str, pero difiere de M. sp. (Quintan Roo, México), M. keaysi str. y M. oxyotus gardneri por su tamaño y otros caracteres morfológicos cuantitativos, así como divergencia evolutiva en secuencias de genes mitocondriales y nucleares. Con base a nuestro análisis filogenético del fragmento parcial del gen citocromo $b$, resolvemos las relaciones polifiléticas de M. keaysi str. y M. pilosatibialis str. Myotis keaysi str. es parafilético en relación con M. ruber y M. simus. M. pilosatibialis str. forma parte de un clado monofilético hermano a este nuevo linaje. Este trabajo contribuye a refinar la taxonomía y sistemática del complejo de especies Myotis pilosatibialis, identifica y describe una especie nueva de Myotis, así como aporta de una manera más amplia a los esfuerzos de caracterizar especies de este género en ambientes neotropicales. Basado en su distribución geográfica, este nuevo clado de murciélagos myotinos se clasifica como paramontano, debido a su distribución a bosques premontanos y montanos de los Chiriquí (Panamá), Valle del Silencio (Costa Rica) y Cordillera Oriental (Ecuador). Estos hábitats son susceptibles a los efectos del cambio climático y la continua destrucción del mismo.

Keywords: Armien's Myotis; Chiriquí province; Cordillera Oriental; cryptic diversity; Myotis armiensis; Neotropics; Valle del Silencio.

(C) 2020 Asociación Mexicana de Mastozoología, www.mastozoologiamexicana.org

\section{Introduction}

Bats of the widely distributed genus Myotis are an excellent model for studies of diversification and historical biogeography (Stadelmann et al. 2007; Ruedi et al. 2013). With ca. 134 species (www.mammaldiversity.org), Myotis is one of the more remarkable mammalian radiations worldwide. Although long considered to be a classic example of an adaptive radiation in temperate regions, more detailed studies of Neotropical (Larsen et al. 2012a, b) and Afrotropical species (Patterson et al. 2019) using molecular data are now uncovering substantial cryptic diversity (Bickford et al. 2007) in tropical regions.

Based on previous systematic revisions (La Val 1973; Hernandez-Meza et al. 2005; Wilson 2008; Moratelli and Wilson 2014; Mantilla-Meluck and Muñoz-Garay 2014), the nominal species $M$. keaysi was partitioned into two 
subspecies: M. k. keaysi J. A. Allen 1914, distributed in the Andes of Colombia, Colombian Caribbean, Perú, Ecuador, Bolivia, and Argentina above 1,100 m, with most specimens known from above $2,000 \mathrm{~m}$ and $M$. $k$. pilosatibialis (La Val 1973), occurring in northern Venezuela, the island of Trinidad, Colombian Caribbean, eastern cordillera of the Colombian Andes, and elsewhere from southern México, southeastward through Central America into northwestern Panamá. Both subspecies are known to occur in sympatry in Caribbean Colombia and the eastern cordillera of Colombia. Although the phylogenetic placement for both is still pending, Mantilla-Meluck and Muñoz-Garay (2014) recognized pilosatibialis as distinct at the species level based on morphology. Based on those findings, Moratelli and Wilson (2014) recommended reassigning the specimens previously assigned to M. keaysi by Stadelmann et al. (2007) and Ruedi et al. (2013) from Yucatán (México) to M. pilosatibialis. Furthermore, Moratelli et al. (2016) and Moratelli et al. (2017) were unable to confidently identify these specimens from Yucatán, México and assigned provisionally a "cf ." (Latin, confer), preceding the specific epithet.

Myotis keaysi as envisioned by Stadelmann et al. 2007 and Ruedi et al. 2013 was identified as a monophyletic clade with considerable geographic structure and at least three different lineages (Larsen et al. 2012a; Chaverri et al. 2016), which were named as follows: M. keaysi (Yucatán Peninsula, México), M. cf. keaysi 2 (México, El Salvador, Guatemala), and an unnamed clade from the mountain tops of Cordillera Oriental from Ecuador and Panamá (Clare et al. 2011; Larsen et al. 2012b) that was later suggested to be $M$. keaysi (Costa Rica) in Chaverri et al. (2016).

In this study, we provided the phylogenetic placement for M. keaysi str. and M. pilosatibialis str. in the Myotis Neotropical radiation and under this phylogenetic framework, we reviewed specimens from the unnamed clade from mountain tops of Chiriquí (Panamá) and Cordillera Oriental (Ecuador). We found that these specimens are distinct from other species of Neotropical Myotis and described this new species based on the General Lineage Concept (GLC), which uses the concept of species as separately evolving metapopulation lineages that can be recognized using diverse secondary recognition criteria (De Queiroz 2007). We apply the criteria used by Florio et al. (2012) as follows: a) identify lineages based on clades from analysis of multiple molecular markers b) employ multivariate procedures such as principal component analysis (PCA) and discriminant function analysis (DFA) to determine morphological variation associated with these phylogenetic groups, and c) use climatic analysis to evaluate the environment and geographic space occupied by the groups supported by covariation of genetic and morphological evidence.

\section{Methods}

Specimens in Panamá were collected under an ongoing project entitled "Caracterización de la epidemiología y ecología de enfermedades zoonóticas trasmitidas por vec- tores (emergentes y reemergentes) en áreas silenciosas y conocidas de Panamá" signed by Instituto Conmemorativo Gorgas and Ministerio del Medio Ambiente de Panamá, with permits SC/A-50-1 and SEX/A-1-19. In Ecuador, specimens were collected under the project "Caracterización de la diversidad biológica y genética de los mamíferos del Ecuador", signed by Pontificia Universidad Católica del Ecuador and Ministerio del Medio Ambiente (MAE), with permits (MAE-DNB-CM-2016-004 and 70-12-2017- DPAN/ $M A E)$. Specimens in both countries were collected with ground-level mist netting and field methods generally followed Galbreath et al. (2019), under guidelines of the American Society of Mammalogists (Sikes et al. 2016) and approved by the University of New Mexico Animal Care and Use Committee.

Specimens examined. Specimens directly examined $(n=72)$ for this research include representatives of Central and South American Myotis, including type specimens (Appendix I). These comprise fluid-preserved specimens, stuffed skins, and skulls deposited in the following institutions: American Museum of Natural History (AMNH); Field Museum of Natural History, Chicago (FMNH); Natural History Museum, University of Kansas (KU); Natural History Museum of Los Angeles County, Los Angeles (LACM); Louisiana State University Museum of Natural Science (LSUMZ); Museum of Vertebrate Zoology, University of California, Berkeley (MVZ); Museum of Southwestern Biology, University of New Mexico (MSB); National Museum of Natural History, Smithsonian Institution (USNM); Museo de Zoología, División de Mastozoología, Pontificia Universidad Católica del Ecuador (QCAZ); Royal Ontario Museum (ROM); Sam Noble Oklahoma Museum of Natural History, University of Oklahoma (SNOMNH); Texas A\&M Biodiversity Research and Teaching Collection, College Station (TCWC); Museum of Texas Tech University (TTU; Dunnum et al. 2018). These specimens were identified according to Wilson (2008), Moratelli and Wilson (2011), Moratelli et al. (2013), Moratelli et al. (2017).

Measurements. All measurements are in millimeters $(\mathrm{mm})$ or grams (body mass) and are from adults. The lengths of head and body (HB), tail, hind foot, ear, and the body weight (mass) were recorded from skin labels and are reported to the nearest millimeter or nearest gram. Forearm length (FA) and third metacarpal length ( $3 \mathrm{ML})$ were directly measured from specimens. Measurements were taken using digital calipers accurate to $0.02 \mathrm{~mm}$. Craniometric measurements were taken under a binocular microscope at low magnification (usually $6 \mathrm{x}$ ). These dimensions were recorded and analyzed to the nearest $0.01 \mathrm{~mm}$, but values were rounded off to $0.1 \mathrm{~mm}$ throughout the text because this is the smallest unit allowing accurate repeatability with calipers (Voss et al. 2013).

Measurements include four external, 14 cranial, and two mandibular dimensions. The measurements and abbreviations are defined as follows: forearm length (FA), from the elbow to the distal end of the forearm including car- 
pals; third metacarpal length (3ML), from the distal end of the forearm including carpals to the distal end of the third metacarpal; length of dorsal hairs (LDH), from the base to the tip of the hair in the fur between the scapulae; length of ventral hairs (LVH) in fur at mid thorax; greatest length of the skull (GLS), from the apex of the upper internal incisors to the occiput; condylocanine length $(\mathrm{CCL})$, from the anterior surface of the upper canines to a line connecting the occipital condyles; condylobasal length $(\mathrm{CBL})$, from the premaxillae to a line connecting the occipital condyles; incisive length $(\mathrm{CIL})$, from the apex of upper internal incisors to a line connecting the occipital condyles; basal length (BAL), from the apex of upper internal incisors to the ventral margin of the foramen magnum; zygomatic breadth (ZB), greatest breadth across the outer margins of the zygomatic arches; mastoid breadth (MAB) greatest breadth across the mastoid region (MAB); braincase breadth $(B C B)$, greatest breadth of the globular part of the braincase; interorbital breadth (IOB), least breadth between the orbits; postorbital breadth (POB), least breadth across frontal posterior to the postorbital bulges; breadth across canines (BAC), greatest breadth across outer edges of the crowns of upper canines, including cingulae; breadth across molars (BAM), greatest breadth across outer edges of the crowns of upper molars; maxillary toothrow length (MTL), from the upper canine to M3; molariform toothrow length (M1-3), from M1 to M3; mandibular length (MAL), from the mandibular symphysis to the condyloid process; and mandibular toothrow length (MAN), from the lower canine to m3. Measurements and abbreviations are further defined in Moratelli et al. (2013). Descriptive statistics (mean and range) were calculated for all dimensions. The cranial index $(C R I=(((I O B+B C B) x$ $\mathrm{GLS}) / 2)$ ) and a modification of the maxillary index (MXI = $(((B A C+B A M) \times M T L) / 2))$ were as used by Baud and Menu (1993) and López-González et al. (2001). We used capitalized colors from (Ridgway 1912).

Principal component analysis (PCA) and discriminant function analysis (DFA) were used to examine overall patterns of skull size and shape variation among samples. We selected the following cranial dimensions representing different axes of length and width of the skull, rostrum and mandible: GLS, CCL, CBL, CIL, BAL, MAB, BCB, IOB, POB, BAC, BAM, MTL, M1-3, MAL, MAN. To obtain a more balanced design for multivariate analysis, we selected a minimum of 4 and maximum of 10 adult specimens, totaling 33 individuals (17 females and 16 males). Males and females were pooled together to enhance analysis. PCA was used to summarize trends in size and shape variation (total data set was considered a unique sample). We conducted a varimax rotation of the loading matrix after PCA in order to have more interpretable factors with a simpler structure that can be obtained using orthogonal rotations. We used rotated PCA scores to test for statistical significance of difference among species. This was assessed by multiple analysis of variance MANOVA, with Pillai's Trace. This previous analysis was followed by one-way ANOVA. A post-hoc multiple comparison Bonferroni corrected approach was used to evaluate pairwise differences among species (Rice1989).

DFA was used to assess craniometric characters that best discriminate samples, with a priori identification of samples (Moratelli et al. 2013). For DFA, probabilities for misclassification rates were also assessed and individuals were resigned using a jackknife procedure. Missing data values were estimated using Amelia R package ( $0 \%$ of total data set) from raw data set (Honaker et al. 2011). We checked for normality assumptions and measurements were log transformed (Zar 1998). Finally, variance-covariance matrices were computed using all variables.

Statistical analyses were performed in software $R(\underline{R}$ Core Team 2020). We used the following $R$ packages as follows: MASS (DFA analysis), stats (PCA analysis), ggplot 2 and ggord (graphics and visualization), factoextra (eigenvalues extraction), psych (varimax rotation), car (MANOVA analysis), rstatix (summary statistics, T-test, ANOVA, adjust P-values for multiple comparisons, formatting and adding significant symbols; Venables and Venables and Ripley 2002; Wickham 2016; Beck 2017; Fox and Weisberg 2019; Revelle 2020; Kassambara 2020; Kassambara and Mundt 2020.

We contrasted the skull size and shape of $M$. sp. $n$. $(n=10)$ from Chiriquí (Panamá) and Cordillera Oriental (Tungurahua Province, Ecuador); M. pilosatibialis str., including the holotype specimen $(n=8)$; M. keaysi str. from Puno and Cuzco, Perú $(n=5)$; M. oxyotus. gardneri, including the holotype specimen $(n=6)$ from Costa Rica and Panamá; and specimens provisionally labelled as $M$. cf. pilosatibialis $(n=4)$ from Quintana Roo, Yucatán Peninsula, México, hereafter called $M$. sp. We included $M$. pilosatibialis str. (El Salvador, Guatemala, Honduras and México) and M.sp. (Quintana Roo, Yucatán, México) due to its close morphological similarity and phylogenetic proximity (Larsen et al. 2012a; Moratelli et al. 2016; Moratelli et al. 2017). Similarly, we included specimens that morphologically match M. oxyotus gardneri La Val 1973, which was recorded in syntopy with the newly identified lineage at Chiriquí Province (Panamá) and Valle del Silencio (Costa Rica). Likewise, we included $M$. keaysi str. from Perú, due to resemblance in external dimensions, cranial morphology and fur traits. Qualitative traits employed here to characterize and distinguish species follow Moratelli et al. (2013). Capitalized color nomenclature follows Ridgway (1912).

DNA Extraction, Sequencing, Editing, and Assembly of partial cytochrome $b$ and nuclear genes. To obtain DNA sequence data, whole DNA was extracted from liver, muscle or wing tissues, following a guanidinium isothiocyanate extraction protocol, E.Z.N.A. Tissue DNA Kit (Omega), and DNeasy Blood \& Tissue Kit (Qiagen). Samples were quantified using Nanodrop ${ }^{\circledR}$ ND-1000 (NanoDrop Technologies, Inc) or Qubit fluorometer kit (Invitrogen), resuspended and diluted to $25 \mathrm{ng} / \mathrm{ul}$ in $\mathrm{ddH}_{2} \mathrm{O}$ prior to amplification.

We relied on different primers and PCR protocols, which are reported as follows: cytochrome $b$ in Hoffmann and Baker 
(2001); Larsen et al. (2012b); and Naidu et al. (2012); nuclear exon and intron genes in Matthee and Davis (2001); Eick et al. (2005); Larsen et al. (2012b); Lack et al. (2010); Roehrs et al. (2010); and Salicini et al. (2011). We targeted $\sim 710 \mathrm{bp}$ of cytochrome- $b$ sequence $(n=11), 1,038 \mathrm{bp}$ of nuclear exon, (RAG2) recombination activating gene II sequence ( $n$ $=13$ ), and intron region of other 3 genes, 402 bp of protein kinase $C$, iota sequence (PRKCl, $n=14$ ), 414 bp signal transducer and activator of transcription $5 \mathrm{~A}$ sequence (STAT5A, $n=14$ ), and 475 bp of thyrotropin sequence (THY, $n=14$ ). Sequencing was conducted using Applied Biosystems 3110 Sequencer of the molecular biology facility at the University of New Mexico (UNM). In Ecuador, successful amplified PCR products were sent for sequencing to the commercial laboratory Macrogen Inc in Seoul, South Korea. Editing and assembly of sequences were performed with Geneious Prime (BioMatters Ltd. 2020).

DNA Extraction and Sequencing of cytochrome oxidase c subunit I. We retrieved partial sequences of cytochrome $c$ oxidase subunit I (657 bp) from mitochondrial genomes for the following species: M. oxyotus gardneri $(n=1)$, M. pilosatibialis str. $(n=2), M$. sp. ( $n=1$, Quintana Roo, Yucatán, México), and M. sp. n. $(n=2)$. DNA was extracted using standard manual extraction methods such as DNeasy Blood \& Tissue Kit (QUIAGEN, Hilden, Germany) following manufacturers guidelines, as well as one open method based on magnetic particle using KingFisher ${ }^{\mathrm{TM}}$ Duo (Thermo Fisher Scientific). DNA was incorporated into double stranded DNA short fragment libraries built following BEST protocol (Mak et al. 2017; Carøe et al. 2018) using BGISEQ-500 adapters. Libraries were sequenced using 100 base paired end read chemistry on a BGISEQ-500 sequencer machine (BGICopenhagen).

Mitogenomes assembly and annotation. Low quality base reads, missing bases and adapters were trimmed followed by adapters removal using Adapter Removal v2 (Lindgreen 2012; Schubert et al. 2016). We built mitochondrial genomes using NOVOPlasty (Dierckxsens et al. 2017) using as reference the mitochondrial genome of Myotis lucifugus accession number (NC_029849.1). Furthermore, annotation was carried on with MitoZ (Meng et al. 2019).

DNA Alignments and Phylogenetic analysis. Alignments of sequences were performed with Geneious Prime (BioMatters Ltd. 2020), using MUSCLE (Edgar 2004). Phylogenetic analysis of mitochondrial and nuclear sequences was conducted with newly generated sequences and sequences retrieved from GenBank for Neotropical species of Myotis previously known to form a monophyletic clade (Ruedi et al. 2013). We included previously generated sequences from GenBank for cytochrome- $b$ for 91 individuals (Ruedi and Mayer 2001; Kawai et al. 2003; Rodriguez and Ammerman 2004; Stadelmann et al. 2004; Kawai et al. 2006; Stadelmann et al. 2007; Baird et al. 2008; Larsen et al. 2012a, b; Patterson et al. 2019), including unpublished data by Parlos et al. (2008); COXI for 51 individuals used in Chaverri et al. (2016); RAG2 for 14 individuals; PRKCI for 13 individuals;
STAT5A for 13 individuals; and THY for 14 individuals (Lack et al. 2010; Roehrs et al. 2010)

Outgroup selection. For cytochrome $b$ phylogeny, we selected three sequences of $M$. gracilis, one sequence of $M$. brandtii and one sequence of $M$. yanbarensis, which are sister species to Neotropical Myotis. For our cytochrome $c$ oxidase subunit I phylogeny, four sequences of $M$. brandtii, and one sequence of $M$. lucifugus were used. In our species tree analysis, we included myotine bats from the Nearctic clade as well, therefore we selected the eastern Palearctic lineage $M$. cf. ikonnikovi as the outgroup.

Maximum likelihood trees were generated using IQTREE with 100 bootstraps and 1000 replicates (Nguyen et al. 2015; Trifinopoulos et al. 2016). We used the program ModelFinder (Kalyaanamoorthy et al. 2017) with Bayesian information criteria (BIC) for selecting a nucleotide substitution model for cytochrome- $b$, cytochrome oxidase $c$ subunit I, exon and intron regions. Heterozygous nuclear introns alleles were statistically resolved using PHASE 2.1.1 (Stephens et al. 2001) prior to the inclusion in further analyses. We used SEQPHASE web server (Flot, 2010) to generate the input files for PHASE. The Bayesian analysis was conducted in MrBayes v.3.2 for partial cytochrome $b$ and cytochrome $c$ oxidase subunit I (Ronquist et al. 2012). The search started with a random tree and the Markov chain was run for 10 million generations with trees sampled every 1,000 generations in two replications. Default values were kept for the "relburning" and "burninfrac" options in MrBayes, therefore the first 25.000, 00 generations were discarded as burn in, and posterior probability estimates of all model parameters were based on the remaining trees. Tree convergence and stationary was accessed in the Bayesian analysis by plotting the likelihood values in Tracer v1.7.1 (Rambaut et al. 2018).

We follow Moratelli et al. (2017) when designating nodal support in the mitochondrial gene trees; for ML analyses there is a strong support for bootstraps values above $\geq 75$ $\%$, moderate support for values $>50 \%$ and $<75 \%$; and negligible for support for values $\leq 50 \%$. For the BI analysis, there are two categories, with significant support in cases in which a node posterior probability was $\geq 0.95$, and insignificant or negligible support for posterior probability values $<0.95$.

Identification of molecular synapomorphies. For the identification of unique molecular synapomorphies for the newly identified lineage, we generated maximum parsimony trees from mitochondrial data sets and intron regions of 3 nuclear genes using PAUP* (Swofford 2003). For these analyses, characters were treated as unordered and equally weighted. We performed a heuristic search with random addition of sequences and tree bisection-reconnection branch swapping. We set maxtree limit to 1000, with the goal of applying a maxtree limit of 100 to each 10 random addition sequence replicate. To measure clade support, 1000 bootstrap replicates were performed on a $50 \%$ majority-rule consensus tree. We used the command describet- 
rees and apolist with delayed transformation (DELTRAN) to obtain a list of molecular synapomorphies. To polarize character state transformation, we used outgroups previously used in maximum likelihood and Bayesian analyses.

Genetic distances. We calculated K2P distances (these were computed for comparisons with previous molecular studies on Neotropical Myotis; e. g, Larsen et al. 2012a, b) expressed as percentages and pairwise genetic distances using uncorrected sequence divergence ( $p$-distances), and modeled in MEGAv10.17 (Kumar et al. 2016) for mitochondrial genes.

Species tree and species delimitation. Under the multispecies coalescent model, we inferred both species tree and species delimitation. For species tree inference we used *BEAST (Heled and Drummond 2010) method using the software suite available in BEAST 2.6.2 (Bouckaert et al. 2019). We used three phased intron and one exon alignments with substitution, clock, and tree models unlinked among all loci. All loci were assigned the lognormal relaxed-clock model using a Yule prior and linear with constant root population size model. We decided not to include mtDNA, due to its potentially strong influence on species tree inference given its higher variability and that assumptions of lower ploidy are not always met (which is modelled by *BEAST; McLean et al. 2016). We ran the analysis for $1 \times 10^{8}$ generations in two replicates, saving the results every 10,000 generations. The first $10 \%$ of each run was discarded as burn-in and assembled using LOGCOMBINER v.1.10.4 to produce a maximum clade credibility tree in TREEANNOTATOR v1.10.4. Likewise, we used Tracer v.1.7.1 to access convergence and stationarity of model parameters based on ESS values and examination of tree files.

We used STACEY v1.2.1 (Species Tree and Estimation classification, Yarely), implemented in BEAST 2.6.2 (Jones 2017; Bouckaert et al. 2019). This method requires no prior assignment of individual to species, and no guided tree. We ran the analysis for $2 \times 10^{8}$ generations in two replicates. After completion, we used Species Delimitation Analyzer (Jones 2015) to process log files and find the distribution over species assignments under two collapse height priors (collapse 0.0001 and 0.0005). Tracer v.1.7.1 was used to assess convergence and stationarity of model parameters based on ESS values and examination of tree files. All newly generated sequences were deposited in GenBank with accession numbers MW025265-MW025275 and MW041968 - MW042028; (see Appendix II for cytochrome $b$ sequences, Appendix III for cytochrome $c$ oxidase subunit I and Appendix IV for nuclear sequences, including previously generated ingroup and outgroup sequences used in this study).

Climatic analysis. Species climatic envelopes have been used for establishing species boundaries in cryptic species (Florio et al. 2012). To evaluate climatic differences among species that are closely related to Myotis sp. n., we only included specimens used in phylogenetic analysis $(n=19)$.
We extracted values for 19 climatic variables in WorldClim at 2.5 arc second resolution (Fick and Hijmans 2017). Prior to conduct PCA analysis, we carried out a Pearson's correlation analysis to indicate presence of multicollinearity among climatic variables. Based on this analysis, we selected nine bioclimatic variables as follows: $\mathrm{BIO} 1=$ Annual Temperature, $\mathrm{BIO} 2=$ Mean Diurnal Range, $\mathrm{BIO} 4=$ Temperature seasonality, $\mathrm{BIO} 5=$ Max Temperature of the Warmest Month, $\mathrm{BIO6}=$ Min Temperature of the Coldest Month seasonality, $\mathrm{BIO} 12=$ Annual Precipitation, $\mathrm{BIO} 13=$ Precipitation of the Wettest Month, BIO14 = Precipitation of the Driest Month and $\mathrm{BIO} 15=$ Precipitation seasonality.

We conducted a principal component analysis to examine the degree of climatic variation among species, then we ran a MANOVA using informative rotated PC's, followed by a post-hoc multiple comparison approach using a Bonferroni corrected approach, to evaluate pairwise differences among species. Statistical analyses were performed in software R ( $\underline{\mathrm{R} \text { Core Team 2020). }}$.

\section{Results}

Phylogenetic analysis. The partial cytochrome $b$ alignment contained 145 sequences with 1, 140 columns, 620 distinct patterns, 434 informative sites, 66 singleton sites and 640 constant sites. ModelFinder found that the Bestfit model was the Hasegawa-Kishono-Yano, with empirical base frequencies allowing for a proportion of invariable sites plus discrete Gamma model (HKY + F + I + G4), whilst our cytochrome $c$ oxidase subunit I alignment contained 61 sequences with 657 columns, 216 distinct patterns, 188 informative sites, 22 singleton sites and 447 constant sites. ModelFinder found Hasegawa-Kishono-Yano, with empirical base frequencies plus discrete Gamma model (HKY + F + G4) as the Best-Fit model according to BIC.

Both maximum likelihood and Bayesian phylogenetic analysis of mitochondrial genes sequences (Figures 1 and 2) from specimens that morphologically match M. pilosatibialis str. sensu La Val (1973), were recovered as part of a monophyletic clade containing specimens from Guatemala, El Salvador, and México. This clade was found well-supported in cytochrome $b$ analyses, with negligible support found in the cytochrome $c$ oxidase subunit I phylogenetic tree. A specimen from Guatemala was geographically closest to the type locality in Honduras, therefore, we followed La Val (1973) in referring to this clade as M. pilosatibialis str.

In our cytochrome $b$ phylogenetic tree, a clade formed by sequences from specimens of $M$ pilosatibialis str. is sister to a well-supported high elevation clade formed by specimens from Chiriquí and Cordillera Oriental (Ecuador), hereafter called $M$. sp. n., whilst our cytochrome $c$ oxidase subunit I, analysis retrieved a supported clade from Costa Rica, Panamá and Ecuador samples as sister to M. sp. (Quintana Roo, Yucatán, México).

The phylogenetic placement of M. sp. (Quintana Roo, Yucatán, México) differs in our cytochrome $b$ phylogenetic analysis, being paraphyletic to a well-supported monophy- 


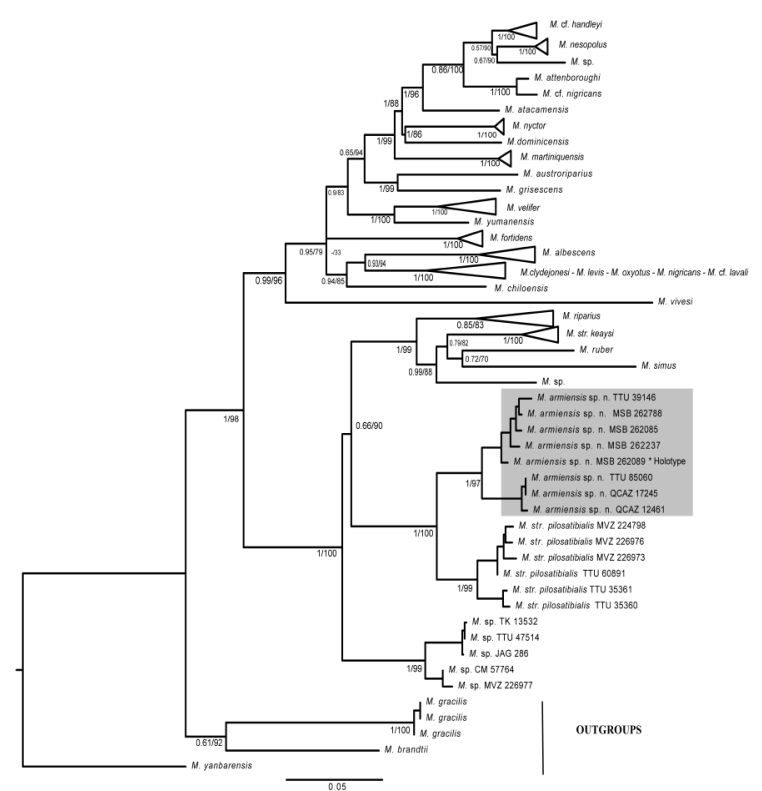

Figure 1. Partial cytochrome $b$ phylogeny resulting from bayesian and maximum likelihood inference, with shaded grey sequences of $M$. armiensis sp. n., including holotype. The Bayesian analysis was conducted in MrBayes and maximum likelihood trees were generated using IQ-TREE with 100 bootstraps and 1000 replicates. Scores are bootstrap and probabilities values. Nodal support is shown right and left of slashes ("/") respectively.

letic clade formed by M. sp. n. + M. pilosatibialis str. and the ruber group (simus, keaysi, ruber, riparius, sp.). M. sp. n. is part of well supported clade in both mitochondrial topologies. Within the ruber group, we were able to obtain a cytochrome $b$ sequence from a specimen that morphologically matches M. keaysi sensu La Val (1973) from Cochabamba, Bolivia which is the specimen geographically nearest to the type locality of Minas at Puno, Perú.

M. sp. n. is genetically distinct using both mitochondrial markers, the genetic pairwise distances between $M$. sp. n. and other species studied range from 6.1 to $12 \%, p$-distance $0.06-0.11$ in partial cytochrome $b$, and from 3.6 to $9.8 \%, p$-distance $0.03-0.08$ in partial cytochrome $c$ oxidase subunit I. In partial cytochrome $b$, we retrieved the lowest value for conspecific populations

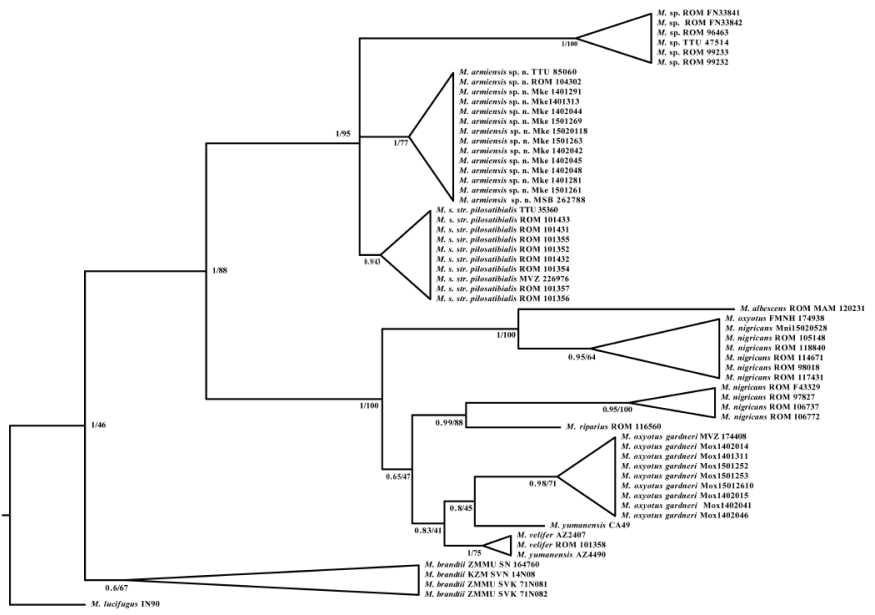

Figure 2. Partial cytochrome oxidase $c$ subunit I phylogeny resulting from bayesian inference and maximum likelihood inference. The Bayesian analysis was conducted in MrBayes and maximum likelihood trees were generated using IQ-TREE with 100 bootstraps and 1000 replicates. Scores are bootstrap and probabilities values. Nodal support is shown right and left of slashes (" /") respectively. from Chiriquí and eastern Cordillera Oriental (Ecuador; $3.1 \%, p$-distance 0.03 ). For cytochrome oxidase c oxidase subunit I, the lowest value was retrieved between conspecific populations from Valle del Silencio (Costa Rica) and Chiriquí Province (Panamá; $0.0 \%$, p-distance 0.00). Distance values are of the same order of magnitude as other interspecific and intraspecific comparisons within the taxa compared (Table 1).

Our species tree analysis readily identified M. sp. n. as genetically distinct from other species in the Neotropical and Nearctic Myotis radiation. Although we recovered relatively low support values for the newly identified clade, this topology also depicts a sister species relationship between conspecific populations from Chiriquí (Panamá) and Cordillera Oriental (Ecuador) as previously shown in our mitochondrial phylogenetic analyses (Figure 3). Results from two STACEY replicates analyses using nuclear data set suggested 20 putative species, under two collapse heights (0.0001 and 0.0005). Among the delimitated species, we found $M$. sp. n. as a candidate to be evaluated under an integrative taxonomy approach using independent data.

Morphological analysis. The principal component analysis comparing all five species extracted two major components that accounted for 53.0 and $30.3 \%$ of the variation (Figure 4; Table 2). The PCA plot shows that M. sp. n. overlaps partially with M. pilosatibialis str., which is due to size and shape similarities, while all of the other species were distinct. M. str. keaysi and M. oxyotus gardneri plotted at the lower left end of PC1 reflecting their larger size, whilst $M$. sp.

Table 1. Matrix of genetic distances (partial cytochrome $b$ and cytochrome $c$ oxidase subunit I) within and among three species of Myotis, where armiensis sp. $\mathrm{n}$. in divided in two clades in cytochrome $b$ analysis and three clades in cytochrome $c$ oxidase subunit I. Below the diagonal:pairwise genetic distance using Kimura 2-parameter model (percentage). On the diagonal within clade distance using the Kimura 2-parameter model (percentage). Above the diagonal:pairwise $p$-distance values. Number of specimens sequenced in parenthesis.

\section{Partial Cytochrome-b}

\begin{tabular}{|c|c|c|c|c|c|}
\hline Species/clades & 1 & 2 & 3 & 4 & 5 \\
\hline 1 M. armiensis sp. n. Panamá (5) & 1.0 & 0.03 & 0.06 & 0.11 & 0.09 \\
\hline 2 M. armiensis sp. n. Cordillera & 3.1 & 0.0 & 0.06 & 0.11 & 0.09 \\
\hline \multicolumn{6}{|l|}{ Oriental (Ecuador) (3) } \\
\hline 3 M. pilosatibialis (6) & 6.2 & 6.1 & 2.0 & 0.11 & 0.11 \\
\hline 4 M. keaysi (1) & 12.0 & 11.7 & 11.7 & n.a & 0.11 \\
\hline \multirow[t]{2}{*}{5 M. sp. (5) } & 9.8 & 10.1 & 10.0 & 12.1 & 2.0 \\
\hline & \multicolumn{5}{|c|}{$\begin{array}{c}\text { Partial Cyto-chrome c oxidase } \\
\text { subunit I }\end{array}$} \\
\hline Species/clades & 1 & 2 & 3 & 4 & 5 \\
\hline 1 M. armiensis sp. n. Panamá (2) & 0.0 & 0.01 & 0.01 & 0.03 & 0.08 \\
\hline 2 M. armiensis sp. n. Cordillera & 1.8 & n.a & 0.01 & 0.03 & 0.08 \\
\hline \multicolumn{6}{|l|}{ Oriental (Ecuador) (1) } \\
\hline $\begin{array}{l}3 \text { M. armiensis sp. n. Costa Rica } \\
\text { (11) }\end{array}$ & 0.0 & 1.8 & 0.0 & 0.03 & 0.08 \\
\hline 4 M. pilosatibialis (6) & 3.6 & 3.8 & 3.6 & 0.0 & 0.07 \\
\hline 5 M. sp. (5) & 9.5 & 8.7 & 9.8 & 8.1 & 1.3 \\
\hline
\end{tabular}




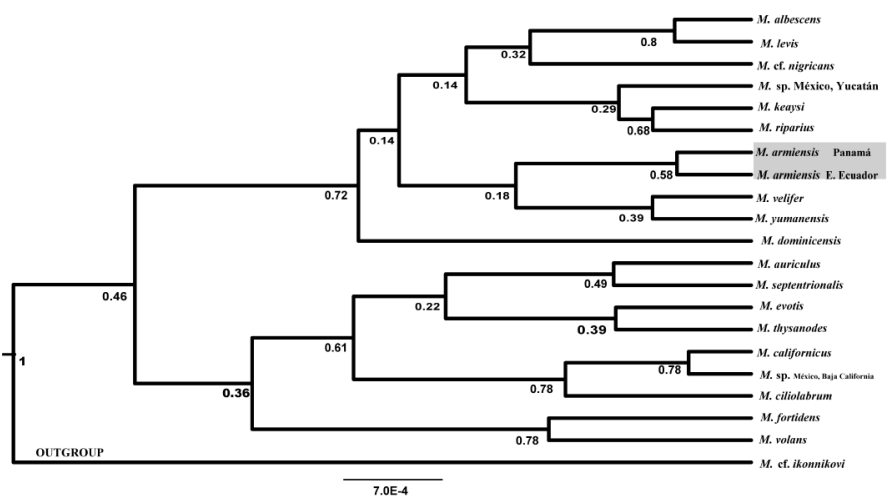

Figure 3. Species tree inferred in *BEAST using multilocus sequence data for New World Myotis. Number under branches represent bayesian posterior probability values with conspecific populations from Ecuador and Panama shaded grey.

(Quintana Roo, Yucatán, México) plotted at the right lower end, which is explained by its small size. PC1 shows variation in size and is influenced most by variables related to length of the skull, having MAL, GLS, CCL, CBL, CIL and M1M3 with loadings above 0.8. PC2 shows shape variation, and it is most influenced by measurements associated with the width of the skull, with $B C B$ and $P O B$ having loadings above 0.8 .

A one-way multivariate analysis of variance suggested there was a statistically significant difference between all species on both PC1 and PC2, as suggested by Pillai's Trace test, $F_{(8,58)}=15.411, P<0.001$. Follow-up ANOVAs showed that this dissimilarity occurred at both PC's $\left(P C 1, F_{(4,29)}=\right.$ $\left.15.9, P<0.05, P C 2, F_{(4,29)}=15.0, P<0.05\right)$. Post-hoc multiple comparison analyses revealed that $M$. sp. $\mathrm{n}$. is different from $M$. oxyotus gardneri $(P<0.01)$, and $M$. str. keaysi $(P<0.05)$

Table 2. Factor loading after PCA and varimax rotation, with Kaiser Normalization for two principal components from a principal component analysis (PCA). The analysis is based on 15 craniometric measurements of five species, including 33 individuals. See Methods for variable abbreviations.

\begin{tabular}{ccc}
\hline Measurements & PC I & PC II \\
\hline MAL & -.939 & .231 \\
MAN & -.695 & .585 \\
GLS & -.914 & .318 \\
CCL & -.862 & .444 \\
CBL & -.866 & .423 \\
CIL & -.944 & .245 \\
BAL & -.754 & .574 \\
MAB & -.751 & .323 \\
BCB & ---- & .921 \\
IOB & -.645 & .564 \\
POB & -.374 & .812 \\
BAC & -.337 & .599 \\
BAM & -.513 & .761 \\
MTL & -.765 & .575 \\
M1-M3 & -.840 & .299 \\
eigenvalues & 11.14 & 30.3 \\
cumulative \% & 53.0 & 83.3 \\
\hline
\end{tabular}

Table 3. Vector coefficient correlations between original variables and discriminant functions (DF1 and DF2) for selected samples of Myotis.

\begin{tabular}{lrr}
\hline & Measurements & DF2 (83.5\%) \\
\hline MAL & -32.71 & -179.89 \\
MAN & 135.04 & 62.82 \\
GLS & 215.37 & -84.56 \\
CCL & -120.75 & -83.33 \\
CBL & 42.31 & -75.27 \\
CIL & -136.83 & -52.95 \\
BAL & 70.81 & -144.96 \\
MAB & 190.98 & 142.86 \\
BCB & 21.57 & 49.32 \\
IOB & .67 & -23.05 \\
POB & 18.80 & -36.78 \\
BAC & -97.68 & 106.43 \\
BAM & 38.63 & -76.04 \\
MTL & -89.95 & -23.80 \\
M1-M3 & 78.38 & 85.67 \\
\hline
\end{tabular}

in PC1, and different from M. sp.(Quintana Roo, Yucatán, México; $P<0.001)$ and $M$. str. pilosatibialis $(P<0.05)$ in $P C 2$. For other comparison, see Appendix V.

Although M. sp. $\mathrm{n}$. is overlapping partially with M. pilosatibialis, our DFA analysis readily distinguishes $M$. sp. n. from other species along the first axis (83.5 \%) and to a lesser extent the second axis (9.9\%, Figure 5; Tabla 3). The jackknifed classification matrix showed that the analysis correctly classified $81.8 \%$ of the specimens, with $M$. sp. n. $70 \%$ correctly classified, M. str. pilosatibialis $75 \%$ correctly classified, M. sp. (Quintana Roo, Yucatán, México) $100 \%$ correctly classified, $M$. str. keaysi $75 \%$ correctly classified, and M. oxyotus gardneri $100 \%$ classified.

Cranial index of $M$. sp. n. (CRI: 50.6) is larger than $M$. str. pilosatibialis (CRI: 47.3), M. sp. (Quintana, Roo, Yucatán, México, CRI: 42.1), but smaller than M. str. keaysi (CRI: 51.5) and M. oxyotus gardneri (CRI: 53.8).

Climatic analysis. Our PCA for climatic variables resulted in three PCA's with eigenvalues $>1$, explaining $85.6 \%$ of the total variation. PCA1 was primarily informative for Min Temperature of the Coldest Month, whilst Mean Diurnal range was the principal driver along PCA2. In contrast

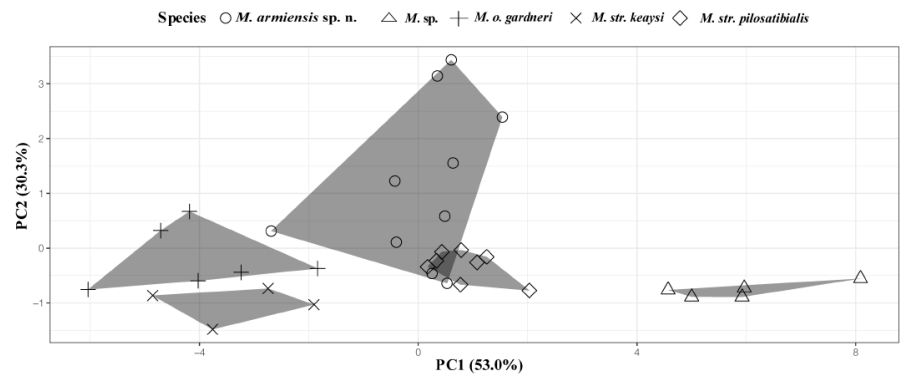

Figure 4. Principal components (PC's) from a PCA based on 15 cranial measurements from 33 individuals. Samples: $M$. armiensis sp. $\mathrm{n}$ (circles), $M$. sp. (triangles), M. oxyotus gardneri ( + symbols), M. keaysi str. ( X symbols), and M. pilosatibialis str. (diamonds). 


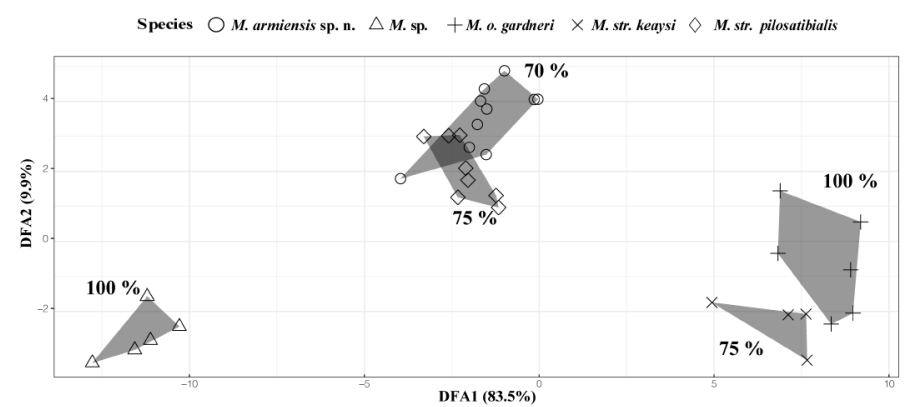

Figure 5. Vector correlation coefficients (loadings) between original variables and discriminant functions (DF1, DF2), with jackknifed percentage of correctly classified specimens for each group. Samples:M. armiensis sp. $\mathrm{n}$ (circles), M. sp (triangles), M. oxyotus gardneri ( + symbol), M. keaysi str. (x symbol), and M. pilosatibialis str.(diamonds).

Annual Temperature was the principal driver of PC3. Oneway multivariate analysis of variance suggested there was a statistically significant difference on $\mathrm{PC1}, \mathrm{PC2}$, and $\mathrm{PC} 3$ as suggested by Pillai's Trace test, $F_{(6,30)}=2.283, P<0.1$. Followup ANOVAs showed that this dissimilarity occurred at PC3 $F_{(2,16)}=4.32, P<0.5$, but not for PC1 $F_{(2,16)}=1.50$ ns and PC2 $F_{(2,16)}=1.50$ ns. Post-hoc multiple comparison analyses did not reveal statistically significant differences in the climatic envelopes of all species, as indicated by extensive overlap (Figure 6; Table 4).

\section{Discussion}

In this report we were able to determine the phylogenetic placement of $M$. pilosatibialis str. based on specimens from Alta Verapaz, Guatemala (San Pedro Carcha, Finca Bethel, $\left.15^{\circ} 0.61^{\prime} \mathrm{N},-90^{\circ} 0.27^{\prime} \mathrm{W}\right)$, the collecting locality for specimens included in the subspecies description (La Val 1973). This locality is ca. $370 \mathrm{~km}$ from the type locality at Francisco Morazán, Honduras ( $14^{\circ} 0.24$ ' $N,-85^{\circ} 0.5^{\prime} \mathrm{W}$ ), therefore we recommend assigning the name pilosatibialis to this species complex, which has a disjunct distribution (primarily low and high elevation species) from southern México, southeastward through Central America into northwestern Panamá, and to the eastern cordillera of the Colombian and Cordillera Oriental (Ecuador). Elsewhere, this complex occurs from the island of Trinidad, to Venezuela and the Colombian Caribbean. This group is characterized by small to medium size, with short woolly hair, and the dorsal surface of tibia partially or entirely covered by fur, which might extend to the hindfoot and across the tibia and onto the plagiopatagium. A flattened occipital region and moderate to high sagittal crest characterize the skull. In agreement with Moratelli et al. (2016) and Moratelli et al. (2017), we included pilosatibialis as part of the ruber group based on shared morphological traits (woolly hair, moderate to high sagittal crest, and flat occipital crest) and close molecular evolutionary proximity. Likewise, we determined the phylogenetic placement of $M$. keaysi str., from voucher specimens collected in Cochabamba, Bolivia ( $-17^{\circ}$ $\left.0.21^{\prime} \mathrm{S},-65^{\circ} 0.6^{\prime} \mathrm{W}\right)$, located $\sim 600 \mathrm{~km}$ distant from the type locality of $M$. keaysi at Inca Mines, Cuzco, Perú $\left(-13^{\circ} 0.30\right.$ 'S ,$\left.-70^{\circ} 0.0 \mathrm{~W}\right)$. Myotis keaysi is another member of the ruber group, with larger external and cranial dimensions, and longer woolly fur, now suggested to be distributed in high elevation sites from the Andes of Colombia, southward to Bolivia and Argentina (Moratelli et al. 2013). According to Mantilla-Meluck and Muñoz-Garay (2014) both species are living in sympatry in the Colombian Caribbean and eastern cordillera of the Andes of Colombia.

Larsen et al.'s $(2012 \mathrm{a}, \mathrm{b})$ molecular study of Neotropical Myotis identified an unnamed clade formed by specimens misidentified as M. nigricans (TTU 39146 from Santa Clara, Chiriquí, Panamá) and M. riparius (TTU 85060 from Azuay, Tungurahua, Ecuador) collected by Robert J. Baker and collaborators in 1983 (Panamá) and 2001 (Sowell-Expedition, Ecuador). Chaverri et al. (2016) referred to this clade as $M$. keaysi based on cytochrome $c$ oxidase subunit I sequences of unvouchered specimens from Valle del Silencio, Costa Rica and one specimen (ROM 104302), collected by the Royal Ontario Museum in Santa Clara, Ojo de Agua, 2 km N of Santa Clara, Panamá.

Prior to those studies, voucher specimen series of Myotis collected from the highlands of Chiriquí Province (USNM, TCWC) had been identified as M. $k$. pilosatibialis. Our bat surveys (in Ecuador in 2017 and Panamá in 2012) provided additional specimens for morphological and genetic studies. Herein, we have examined specimens assigned to the unnamed clade sensu Larsen et al. (2012 a, b), and found morphometric and genetic differences that support recognition of a new species. We propose that populations from Chiriquí Province (Panamá) and Cordillera Oriental (Ecuador) represent a new species, which is described as follows:

\section{Myotis armiensis, species novum \\ Armien's Myotis, Myotis de Armién}

Figure 7, 8, and 9; Tables 5 and 6

Myotis keaysi pilosatibialis, La Val, 1973, part

Myotis keaysi pilosatibialis, Hernandez-Meza et al. 2005, part.

Myotis keaysi pilosatibialis, Wilson, 2008, part.

Myotis nigricans, Larsen et al. 2012a, part.

Myotis riparius, Larsen et al. 2012b, part.

Myotis keaysi, Chaverri et al. 2016, part.

Myotis cf. pilosatibialis, Moratelli et al. 2016, part.

Myotis cf. pilosatibialis, Moratelli et al. 2017, part.

Holotype and type locality. Voucher MSB 262089; adult male; preserved as skin, skull and skeleton (Figures 8 and 9) at the Museum of Southwestern Biology (MSB), University of New Mexico collected on 20 March 2012 by Joseph A. Cook and collaborators (Tropical Biology Class 2012 and Instituto Conmemorativo Gorgas de Estudios de la Salud) at La Amistad International Park Ranger Station $\left(8^{\circ} 89^{\prime} \mathrm{N}\right.$, $-82^{\circ} 61^{\prime}$ W, elevation 2, $214 \mathrm{~m}$ ), Bugaba District, Chiriquí Province, Panamá. Tissues deposited at the same museum (NK 209314, LN2 preservation), with additional tissues at Instituto Gorgas, Panama City $\left(-80^{\circ} \mathrm{C}\right.$ preservation). The specimen is well preserved. The measurement for the forearm (44 $\mathrm{mm}$ ) recorded on the specimen tag is incorrect and should be $\mathrm{FA}=39 \mathrm{~mm}$ as now recorded in the Arctos Museum Database. 


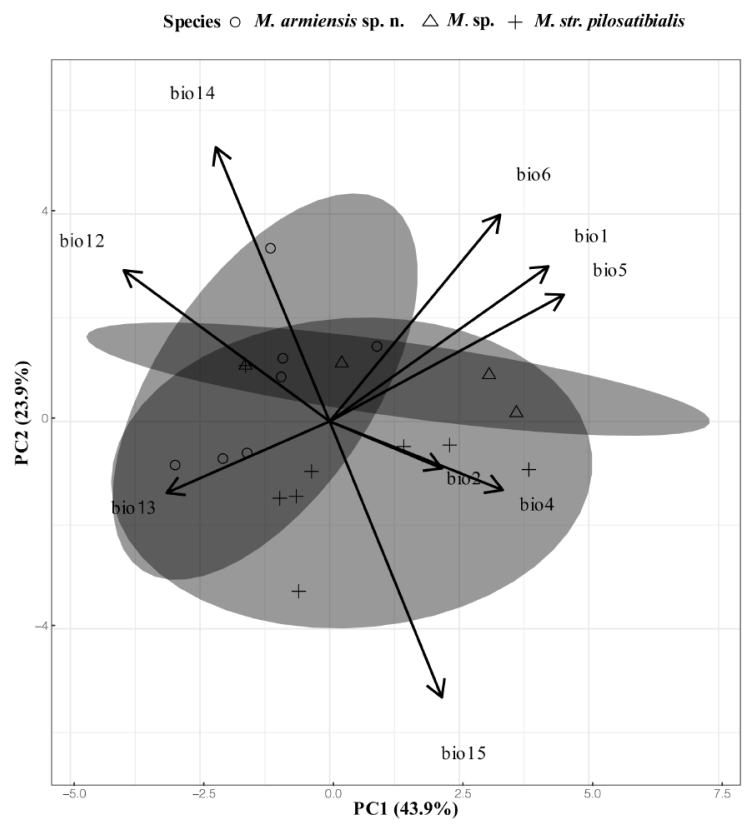

Figure 6. Principal component (PC's) from a PCA based on 9 bioclimatic variables extracted from 19 distribution localities of pilosatibialis species complex, with confidence ellipses and corresponding vectors correlations of climatic variables with the first two eigenvectors. Samples:M. armiensis sp. n. (circles), M. sp. (triangles), and M. pilosatibialis str.(+ symbols).

Paratypes. Nineteen additional specimens were collected from Chiriquí Province, Panamá and Cordillera Oriental (Ecuador). Two specimens were designated as paratypes based on genetic identification, (partial cytochrome b), morphometrics and qualitative data: skin of one adult female (MSB 262085), collected by Joseph A. Cook and collaborators, 20 March 2012; skin and skull of one female, adult (TTU 85060) collected by Robert J. Baker and collaborators (Sowell Expedition-Ecuador, 2001), 24 July 2001.

Six paratypes identified solely by genetic identification (partial cytochrome b) were collected at Bugaba District,

Table 4. Factor loading after PCA and varimax rotation, with Kaiser Normalization for three principal components from a principal component analysis (PCA). The analysis is based on 9 bioclimatic variables, including 19 localities.

\begin{tabular}{lrrr}
\hline \multicolumn{1}{c}{ Climatic variable } & PC I & PC II & PCIII \\
\hline Annual Mean Temperature & \multicolumn{1}{c}{.972} & \multicolumn{1}{c}{.209} & .086 \\
Mean Diurnal Range & -.013 & \multicolumn{1}{c}{.697} & .027 \\
Temperature Seasonality & \multicolumn{1}{c}{.242} & \multicolumn{1}{c}{.633} & .287 \\
Max Temperature of the Warmest Month & \multicolumn{1}{c}{.923} & \multicolumn{1}{c}{.337} & .128 \\
Min Temperature of the Coldest Month & \multicolumn{1}{c}{.988} & -.037 & -.036 \\
Annual Precipitation & -.157 & -.820 & -.480 \\
Precipitation of the Wettest Month & -.241 & -.883 & .243 \\
Precipitation of the Driest Month & -.048 & -.086 & -.965 \\
Precipitation Seasonality & .047 & .073 & .973 \\
eigenvalues & 2.9 & 2.5 & 2.2 \\
\% of variance explained & 32.4 & 27.8 & 25.3 \\
cumulative \% & 32.4 & 60.2 & 85.6 \\
\hline
\end{tabular}

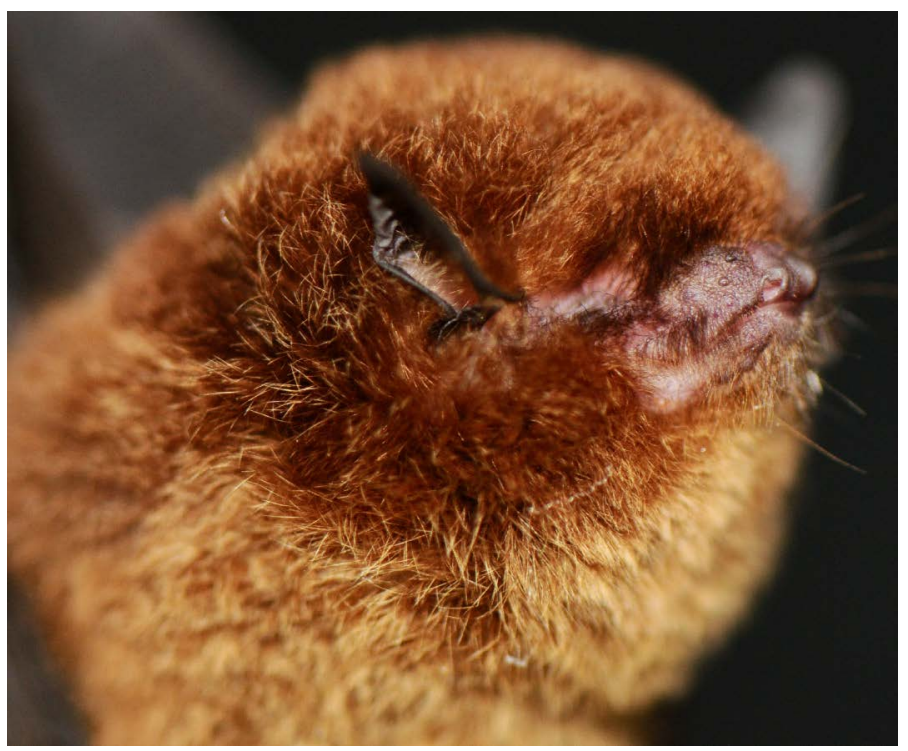

Figure 7. Adult female of Myotis armiensis sp. n. (QCAZ 17245) captured at Cabañas del Aliso, Cosanga, Napo Province, Ecuador. Photographed by Carlos Carrión Bonilla.

Chiriquí Province, Panamá [one adult male (MSB 262237) collected by Joseph A. Cook and collaborators, 20 March 2012)], Jurutungo, Río Sereno, Renacimiento District, Chiriquí Province, Panamá [sex unknown (MSB 262788), collected by Gorgas Institute field researchers, 6 May 2011], Santa Clara, Renacimiento District, Chiriquí Province, Panamá [one female, age unknown (TTU 39146), collected by Robert J. Baker, 19 January 1983], Cabañas del Aliso, Cosanga, Napo Province, Ecuador [one female, age adult, (QCAZ 17245) collected by Carlos A. Carrión Bonilla, 13 December 2017), Yantzaza, Campo Minero Fruta del Norte, Zamora Chinchipe, Ecuador [male, adult (QCAZ 12461), collected by Paula Iturralde, 3 March 2011]. Another specimen from Ojo de Agua, $2 \mathrm{~km} N$ of Santa Clara, Renacimiento District, Chiriquí Province, Panamá (ROM 104302), collected by Burton Lim and Eamon O'Toole, on 8 March 1995 was identified based on barcode cytochrome $c$ oxidase subunit I.

Ten paratypes identified with morphometric analysis of craniometric measurement analysis and qualitative morphological of skins and skulls were collected from La Amistad International Park Ranger Station, Bugaba District, Chiriquí Province, Panamá [(two females, adults (MSB 262217-18, only skins were studied, no skulls available) collected by Joseph A. Cook and collaborators, 20 March 2012)]; Cerro Punta, Casa Tiley, Tierras Altas District, Chiriquí Province, Panamá [female, adult (USNM 323599, by Handley, C. and Greenwell, F.M., 6 March, 1962)]; El Volcán 2 min S. W, Tierras Altas District, Chiriquí Province, Panamá [two females, adults, (USNM 331942, USNM 331943, by Tyson E, collected 21 March 1962)]; Cuesta de Piedra, Tierras Altas District Chiriquí Province, Panamá [female, adult (USNM 331953, by Tyson E, 28 March 1962)]; 36 km, north of Concepción, Bugaba District, Chiriquí Province, Panamá [five females, adults (TCWC 12655-59, by Patten, D.R., 8 June 1964)]. We did not include any specimens from Costa Rica in the type series, because the Chaverri et al. (2016) study was unvouchered, and therefore morphological confirma- 
Table 6. Selected measurements, cranial index, body mass (adults males and females[N]). Mean, (Minimum-Maxima) and sample size ( $n$ ). See methods for variable abbreviations.

\begin{tabular}{|c|c|c|c|c|c|}
\hline Characters & $\begin{array}{l}\text { M. armiensis sp. } n . \\
\text { Chiriquí (Panamá) and Cor- } \\
\text { dillera Oriental (Ecuador) }\end{array}$ & $\begin{array}{l}\text { M. keaysi str. } \\
\text { Perú }\end{array}$ & $\begin{array}{l}\text { M. pilosatibialis str. } \\
\text { El Salvador Honduras } \\
\text { México }\end{array}$ & $\begin{array}{c}\text { M.sp. } \\
\text { Quintana Roo, Yucatán, } \\
\text { México }\end{array}$ & $\begin{array}{c}\text { M. oxyotus gardneri } \\
\text { Costa Rica and Panamá }\end{array}$ \\
\hline Body mass & $\begin{array}{c}5.0(4.5-5.6) \\
n=10\end{array}$ & $\begin{array}{c}6.0 \\
n=1\end{array}$ & $\begin{array}{c}6.1 \\
n=1\end{array}$ & & $\begin{array}{c}8 \\
n=1\end{array}$ \\
\hline $\mathrm{HB}$ & $\begin{array}{c}86(77-92) \\
n=12\end{array}$ & $\begin{array}{l}94.0 \\
n=1\end{array}$ & & & $\begin{array}{c}93.0(87-98) \\
n=3\end{array}$ \\
\hline Tail & $\begin{array}{c}39(32-48) \\
n=13\end{array}$ & $\begin{array}{l}42.0 \\
n=1\end{array}$ & & & $\begin{array}{c}40.3(39-43) \\
n=3\end{array}$ \\
\hline Foot & $\begin{array}{c}8(7-10) \\
n=13\end{array}$ & $\begin{array}{c}8.0 \\
n=1\end{array}$ & & & $\begin{array}{c}8.3(8-9) \\
n=3\end{array}$ \\
\hline Ear & $\begin{array}{c}13(11-14) \\
n=13\end{array}$ & $\begin{array}{l}14.0 \\
n=1\end{array}$ & & & $\begin{array}{c}15.7(15-16) \\
n=3\end{array}$ \\
\hline LDF & $\begin{array}{c}6.2(5.3-7.4) \\
n=10\end{array}$ & & & & $\begin{array}{c}7.7(7.4-7.9) \\
n=3\end{array}$ \\
\hline LVF & $\begin{array}{c}6.3(4.5-8.3) \\
n=10\end{array}$ & & & & $\begin{array}{c}6.6(5.6-7.2) \\
n=3\end{array}$ \\
\hline FA & $\begin{array}{c}38.0(36.3-39.4) \\
n=13\end{array}$ & $\begin{array}{l}40.2 \\
n=1\end{array}$ & $\begin{array}{c}35.9(34.3-37.1) \\
n=5\end{array}$ & $\begin{array}{c}32.6(31.8-34.4) \\
n=4\end{array}$ & $\begin{array}{c}40.4(38.0-42.8) \\
n=6\end{array}$ \\
\hline $3 \mathrm{MC}$ & $\begin{array}{c}34.3(32.9-35.9) \\
n=13\end{array}$ & $\begin{array}{l}36.8 \\
n=1\end{array}$ & $\begin{array}{c}33.2(32.1-34.4) \\
n=5\end{array}$ & $\begin{array}{c}29.3(27.7-30.4) \\
n=4\end{array}$ & $\begin{array}{c}36.3(34.5-38.6) \\
n=6\end{array}$ \\
\hline GLS & $\begin{array}{c}13.5(13.0-14.0) \\
n=10\end{array}$ & $\begin{array}{c}14.5(14.1-15.0) \\
n=5\end{array}$ & $\begin{array}{c}13.6(13.5-13.9) \\
n=8\end{array}$ & $\begin{array}{c}12.7\left(\begin{array}{c}(12.6-13.0) \\
n=4\end{array}\right.\end{array}$ & $\begin{array}{c}14.5(14.1-15.0) \\
n=6\end{array}$ \\
\hline $\mathrm{CCL}$ & $\begin{array}{c}12.1(11.7-12.5) \\
n=10\end{array}$ & $\begin{array}{c}12.6(12.0-13.0) \\
n=5\end{array}$ & $\begin{array}{c}12.1(11.8-12.3) \\
n=8\end{array}$ & $\begin{array}{c}11.4(11.2-11.7) \\
n=4\end{array}$ & $\begin{array}{c}12.8(12.3-13.3) \\
n=6\end{array}$ \\
\hline CBL & $\begin{array}{c}12.7(12.3-13.0) \\
n=10\end{array}$ & $\begin{array}{c}13.3(12.6-13.8) \\
n=5\end{array}$ & $\begin{array}{c}12.7(12.4-12.9) \\
n=8\end{array}$ & $\begin{array}{c}12.1(11.7-12.4) \\
n=4\end{array}$ & $\begin{array}{c}13.5(13.1-14.1) \\
n=6\end{array}$ \\
\hline CIL & $\begin{array}{c}12.7(11.9-13.2) \\
n=10\end{array}$ & $\begin{array}{c}13.5(12.9-14.0) \\
n=5\end{array}$ & $\begin{array}{c}12.9(12.7-13.1) \\
n=8\end{array}$ & $\begin{array}{c}12.1(11.8-12.5) \\
n=4\end{array}$ & $\begin{array}{c}13.7(13.2-14.2) \\
n=6\end{array}$ \\
\hline BAL & $\begin{array}{c}11.7(11.3-12.1) \\
n=10\end{array}$ & $\begin{array}{c}12.1(11.5-12.5) \\
n=5\end{array}$ & $\begin{array}{c}11.6(11.3-11.9) \\
n=8\end{array}$ & $\begin{array}{c}11.0(10.7-11.3) \\
n=4\end{array}$ & $\begin{array}{c}12.4(12.0-12.8) \\
n=6\end{array}$ \\
\hline ZB & $\begin{array}{c}8.5(7.9-8.8) \\
n=8\end{array}$ & $\begin{array}{c}8.6(8.5-8.8) \\
n=4\end{array}$ & $\begin{array}{c}8.2(8.1-8.4) \\
n=6\end{array}$ & & $\begin{array}{c}8.9 \\
n=1\end{array}$ \\
\hline MAB & $\begin{array}{c}7.0(6.6-7.4) \\
n=10\end{array}$ & $\begin{array}{c}7.0(6.9-7.2) \\
n=5\end{array}$ & $\begin{array}{c}7.0(6.9-7.2) \\
n=8\end{array}$ & $\begin{array}{c}6.7(6.6-6.7) \\
n=4\end{array}$ & $\begin{array}{c}7.3(7.1-7.4) \\
n=6\end{array}$ \\
\hline $\mathrm{BCB}$ & $\begin{array}{c}6.8(6.2-7.3) \\
\quad n=10\end{array}$ & $\begin{array}{c}6.5(6.4-6.5) \\
n=5\end{array}$ & $\begin{array}{c}6.3(6.1-6.5) \\
n=8\end{array}$ & $\begin{array}{c}5.9(5.8-6.0) \\
n=4\end{array}$ & $\begin{array}{c}6.8(6.6-7.0) \\
n=6\end{array}$ \\
\hline IOB & $\begin{array}{c}4.5(4.2-4.8) \\
\quad n=10\end{array}$ & $\begin{array}{c}4.7(4.5-4.9) \\
\quad n=5\end{array}$ & $\begin{array}{c}4.3(4.2-4.5) \\
\quad n=8\end{array}$ & $\begin{array}{c}4.0(3.9-4.1) \\
\quad n=4\end{array}$ & $\begin{array}{c}4.7(4.5-4.9) \\
\quad n=6\end{array}$ \\
\hline POB & $\begin{array}{c}3.6(3.2-4.2) \\
n=10\end{array}$ & $\begin{array}{c}3.6(3.4-3.8) \\
n=4\end{array}$ & $\begin{array}{c}3.4(3.3-3.5) \\
n=8\end{array}$ & $\begin{array}{c}3.1(3.1-3.2) \\
n=4\end{array}$ & $\begin{array}{c}3.9(3.8-4-0) \\
n=6\end{array}$ \\
\hline BAC & $\begin{array}{c}3.6(3.4-4.0) \\
n=10\end{array}$ & $\begin{array}{c}3.6(3.5-3.7) \\
n=5\end{array}$ & $\begin{array}{c}3.6(3.5-3.8) \\
n=8\end{array}$ & $\begin{array}{c}3.3(3.2-3.4) \\
n=4\end{array}$ & $\begin{array}{c}3.6(3.4-3.8) \\
n=6\end{array}$ \\
\hline BAM & $\begin{array}{c}5.5(5.3-6.0) \\
n=10\end{array}$ & $\begin{array}{c}5.6(5.4-5.8) \\
n=5\end{array}$ & $\begin{array}{c}5.3(5.2-5.5) \\
n=8\end{array}$ & $\begin{array}{c}4.9(4.7-5.0) \\
\quad n=4\end{array}$ & $\begin{array}{c}5.7(5.5-5.8) \\
\quad n=6\end{array}$ \\
\hline MTL & $\begin{array}{c}5.2(5.1-5.4) \\
\quad n=10\end{array}$ & $\begin{array}{c}5.5(5.2-5.6) \\
n=5\end{array}$ & $\begin{array}{c}5.1(5.0-5.2) \\
\quad n=8\end{array}$ & $\begin{array}{c}4.8(4.6-4.9) \\
\quad n=4\end{array}$ & $\begin{array}{c}5.5(5.4-5.6) \\
n=6\end{array}$ \\
\hline M1-3 & $\begin{array}{c}2.9(2.5-3.0) \\
n=10\end{array}$ & $\begin{array}{c}3.1(3.0-3.3) \\
n=5\end{array}$ & $\begin{array}{c}2.9(2.8-3.0) \\
n=8\end{array}$ & $\begin{array}{c}2.6(2.5-2.6) \\
n=4\end{array}$ & $\begin{array}{c}3.1(3.1-3.2) \\
n=6\end{array}$ \\
\hline MAL & $\begin{array}{c}9.6(8.9-10.3) \\
n=10\end{array}$ & $\begin{array}{c}10.2(9.9-10.5) \\
n=5\end{array}$ & $\begin{array}{c}9.6(9.5-9.7) \\
n=8\end{array}$ & $\begin{array}{c}9.1(8.8-9.3) \\
n=4\end{array}$ & $\begin{array}{c}10.4(10.0-10.9) \\
n=6\end{array}$ \\
\hline MAN & $\begin{array}{c}5.5(5.3-5.7) \\
n=10\end{array}$ & $\begin{array}{c}5.8(5.6-5.9) \\
\quad n=5\end{array}$ & $\begin{array}{c}5.5(5.4-5.7) \\
n=8\end{array}$ & $\begin{array}{c}5.1(4.9-5.2) \\
\quad n=4\end{array}$ & $\begin{array}{c}5.7(5.7-5.9) \\
n=6\end{array}$ \\
\hline CRI & $\begin{array}{c}50.6(47.0-53.7) \\
n=10\end{array}$ & $\begin{array}{c}51.5(49.7-53.9) \\
\quad n=5\end{array}$ & $\begin{array}{c}47.3(45.8-49.1) \\
n=8\end{array}$ & $\begin{array}{c}42.1(41.1-43.3) \\
n=4\end{array}$ & $\begin{array}{c}53.8(50.7-56.0) \\
n=6\end{array}$ \\
\hline MAX & $\begin{array}{c}18.1(17.2-19.6) \\
n=10\end{array}$ & $\begin{array}{c}18.8(17.6-19.9) \\
n=5\end{array}$ & $\begin{array}{c}17.3(16.7-17.9) \\
n=8\end{array}$ & $\begin{array}{c}15.0(14.0-15.5) \\
n=4\end{array}$ & $\begin{array}{c}19.2(18.4-19.8) \\
n=6\end{array}$ \\
\hline
\end{tabular}

tion is not possible.

Distribution. Myotis armiensis sp. $\mathrm{n}$. is known from the premontane and montane forest of Chiriquí Province, Panamá, extending its distribution into La Amistad International Park in Panamá (Las Nubes Rangers Station) and Costa Rica (Valle del Silencio). Elevation in Panamá and
Costa Rica varies from $975 \mathrm{~m}$ to $2,500 \mathrm{~m}$ : Concepción ( $\approx$ $\left.8^{\circ} .51^{\prime} \mathrm{N},-82^{\circ} .62^{\prime} \mathrm{W}, 2,011 \mathrm{~m}\right)$, Cerro Punta $\left(8^{\circ} .88^{\prime} \mathrm{N},-82^{\circ} .73^{\prime}\right.$ W, 1,280 m ), Cuesta de la Piedra $\left(8^{\circ} .88^{\prime} \mathrm{N},-82^{\circ} .73^{\prime} \mathrm{W}, 975\right.$ $\mathrm{m})$, El Volcán $\left(8^{\circ} .88^{\prime} \mathrm{N},-82^{\circ} .73 \mathrm{~W}, 1,280 \mathrm{~m}\right)$, Parque Internacional la Amistad Ranger Station: $\left(8^{\circ} .89^{\prime} \mathrm{N},-82^{\circ} .61 \mathrm{~W}, 2\right.$, $214 \mathrm{~m})$, Jurutungo, Río Sereno $\left(8^{\circ} .9^{\prime} \mathrm{N},-82^{\circ} .73 \mathrm{~W}, 2,219 \mathrm{~m}\right)$, 


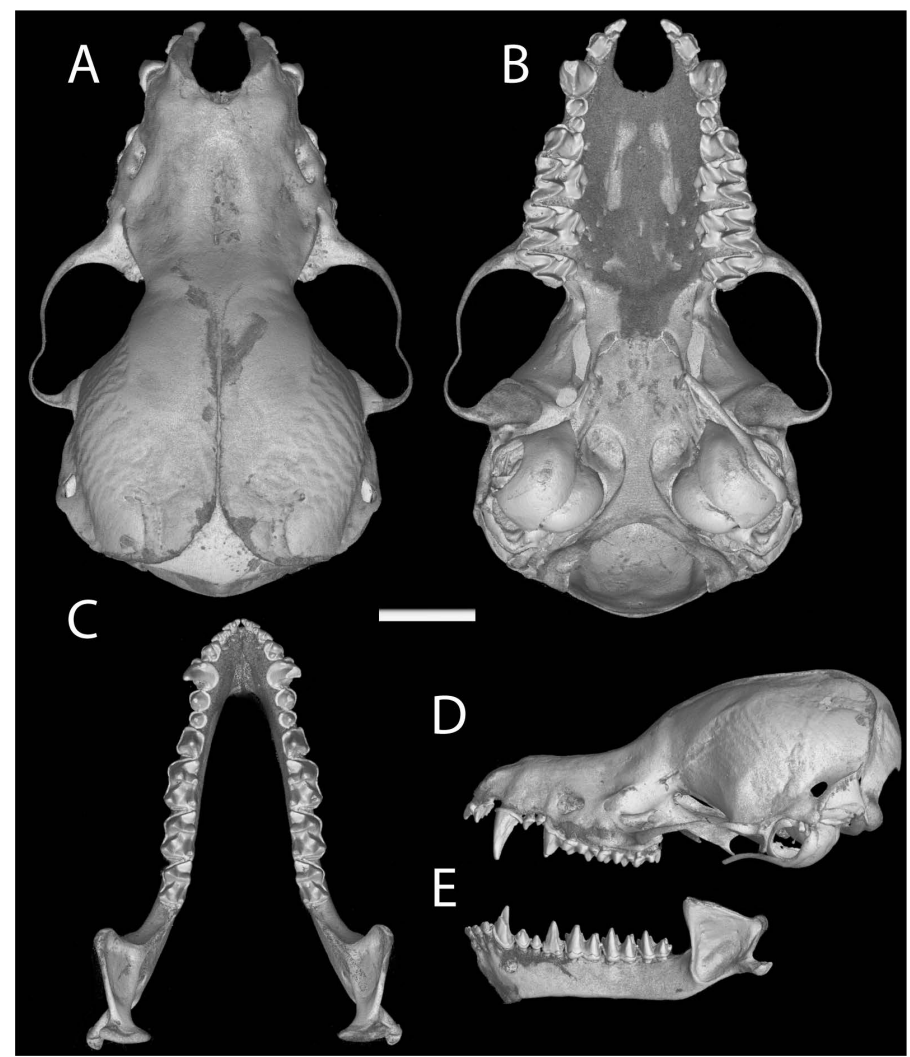

Figure 8. Dorsal (A) and ventral view (B) of the cranium, dorsal view of the mandible (C), and lateral view of the cranium (D) and mandible of the holotype of $M$. armiensis sp. n. (MSB 262089). Scale bar $=5 \mathrm{~mm}$. Photograph taken by John Korbin (Sandia National Laboratory-New Mexico, USA).

Santa Clara ( $\left.\approx 8^{\circ} .83^{\prime} \mathrm{N},-82^{\circ} .75^{\prime} \mathrm{W}, \approx 1,178 \mathrm{~m}\right)$, Ojo de Agua, Santa Clara $\left(8^{\circ} 42^{\prime} \mathrm{N},-82^{\circ} .45 \mathrm{~W}, 1,500 \mathrm{~m}\right)$, Valle del Silencio, Costa Rica $\left(9^{\circ} 11^{\prime} \mathrm{N},-82^{\circ} .96 \mathrm{~W}, 2,500 \mathrm{~m}\right)$. In Ecuador, M. armiensis sp. $\mathrm{n}$. is known from Cordillera Oriental. Elevation in Ecuador varies from 1,200 m to 2,249 m: Yantzaza, Campo Minero Fruta del Norte, Zamora Chinchipe $\left(-3^{\circ} .75^{\prime} \mathrm{S}\right.$, $\left.-78^{\circ} .53^{\prime} \mathrm{W}, 1,200 \mathrm{~m}\right)$, Colonia Azuay, Tungurahua Province, Ecuador (-1 $\left.1^{\circ} .34^{\prime} \mathrm{S},-78.20^{\circ}, 1,660 \mathrm{~m}\right)$, Cabañas el Aliso, Sector Las Caucheras, Quijos, Napo Province $\left(-3^{\circ} .75^{\prime} \mathrm{S},-78^{\circ} .53^{\prime}\right.$ W, 2,249 m). See Figure 10 for species distribution in Costa Rica, Panamá and Ecuador.

Etimology. Myotis armiensis honors Dr. Blas Armién in recognition of his outstanding contributions to research in zoonotic emergent diseases, public health, and mammalogy in Panamá. Over two decades, he has supported the systematic development of holistic museum collections, including associated cryogenic biorepositories and parasites. This infrastructure $(>11,000$ specimens) is now the basis for new insights into temporal and spatial aspects of the biology of Panama's mammals and associated parasites and pathogens.

Diagnosis. Due to the dearth of availability of substantial specimen material and despite the lack of a single morphological character that consistently distinguishes $M$. armiensis from the rest of Neotropical congeners, Myotis armiensis can be distinguished by a combination of the following morphological traits: pelage is short and woolly, dorsal and ventral fur bicolored; insertion of the plagiopatagium occurs
Table 5. Selected measurements $(\mathrm{mm})$ and body weight $(\mathrm{g})$ of the holotype (MSB 262089) and paratype material of Myotis armiensis. See methods for variable abbreviations.

\begin{tabular}{|c|c|c|}
\hline Characters & MSB 262089 & Paratypes \\
\hline Body mass & 5 & $5(4.5-5.6) n=9$ \\
\hline $\mathrm{HB}$ & 90 & $85(77-92) n=11$ \\
\hline Tail & 38 & $39(32-48) n=12$ \\
\hline Foot & 8 & $8(7-10) n=12$ \\
\hline Ear & 13 & $14(11-14) n=12$ \\
\hline LDF & 6.4 & $6.1(5.3-7.4) n=9$ \\
\hline LVF & 7.2 & $6.2(4.5-7.4) n=9$ \\
\hline FA & 37.1 & $38.1(36.3-39.4) n=12$ \\
\hline $3 \mathrm{MC}$ & 34 & $34.3(32.9-35.9) n=12$ \\
\hline GLS & 13.3 & $13.5(13.0-14.0) n=9$ \\
\hline $\mathrm{CCL}$ & 12.2 & $12.1(11.7-12.5) n=9$ \\
\hline CBL & 12.3 & $12.8(12.5-13.0) n=9$ \\
\hline $\mathrm{CIL}$ & 11.9 & $12.8(12.2-13.2) n=9$ \\
\hline BAL & 12.1 & $11.6(11.3-11.9) n=9$ \\
\hline ZB & 7.9 & $8.6(8.0-8.8) n=7$ \\
\hline MAB & 6.6 & $7.1(6.6-7.4) n=9$ \\
\hline $\mathrm{BCB}$ & 7.3 & $6.8(6.2-7.2) n=9$ \\
\hline IOB & 4.4 & $4.6(4.2-4.8) n=9$ \\
\hline POB & 4.2 & $3.5(3.2-3.7) n=9$ \\
\hline $\mathrm{BAC}$ & 3.6 & $3.7(3.4-4.0) n=9$ \\
\hline BAM & 5.4 & $5.6(5.3-6.0) n=9$ \\
\hline MTL & 5.2 & $5.2(5.0-5.4) n=9$ \\
\hline$M 1-3$ & 2.7 & $2.9(2.5-3.0) n=9$ \\
\hline MAL & 9.5 & $9.6(8.9-10.3) n=9$ \\
\hline MAN & 5.7 & $5.5(5.3-5.7) n=9$ \\
\hline
\end{tabular}

on the foot at the level of the base of toes by a wide membrane; lack or relatively low presence of fur on dorsal surface of tibia, foot and plagiopatagium, and border of the uropatagium without a fringe; skull is moderately large; forehead is steeply sloping; rostrum is long; lambdoidal crest is present and high; sagittal crest present, with height from low to medium; occipital crest is absent; occipital region flattened and the shape of the braincase is globular.

Myotis armiensis can be readily distinguished from Myotis congeners from Central and South America based on gene trees [partial sequence of cytochrome- $b$ ( $~ 710 \mathrm{pb})$ and partial cytochrome $c$ oxidase subunit I ( $\sim 657 \mathrm{pb})]$ and species tree phylogenetic analysis of one exon: recombination activating gene II (RAG2), and 3 intron regions: protein kinase $C$, iota (PRKCl), signal transducer and activator of transcription 5A (STAT5A), and thyrotropin (THY). Finally, molecular synapomorphies in mitochondrial and intron genes regions sequences support the species level recognition of M. armiensis sp. $\mathrm{n}$. compared to other species in the New World Myotis radiation (Appendix VI-X). These served as diagnostic characters for the species.

Description. A medium to large species of Myotis (FA 36.3-39.4 mm, $n=13$ and weight 4.5-5.6 gr, $n=10$ ); other 


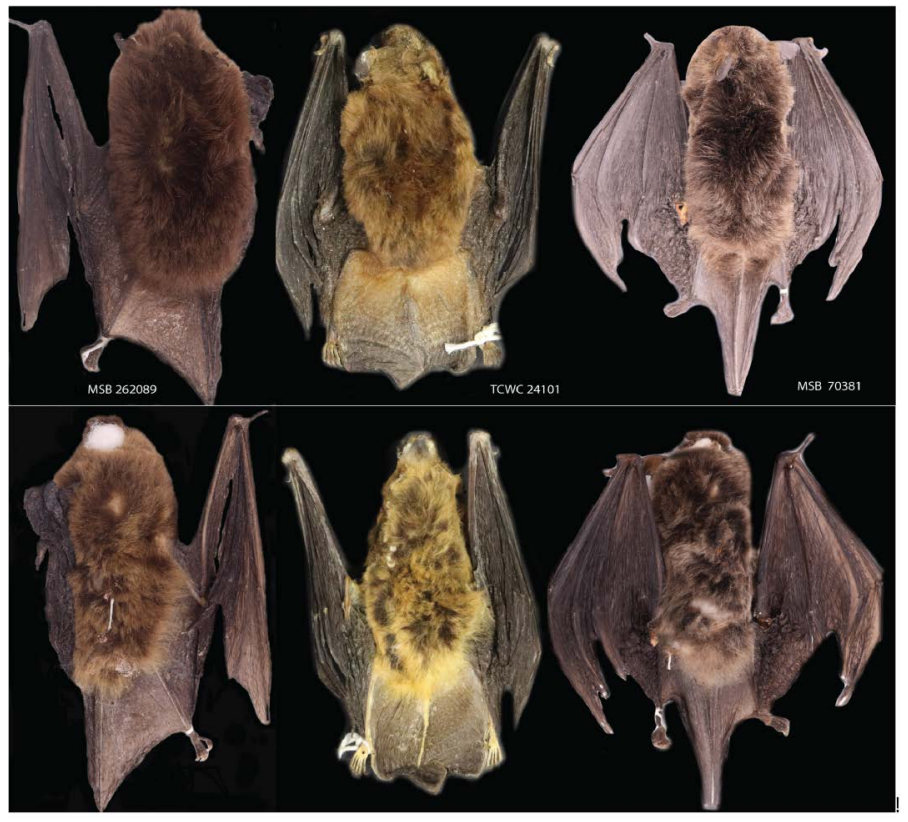

Figure 9. Dorsal and ventral views of the skins of the holotype of M. armiensis sp. $\mathrm{n}$. (MSB 262089), M. pilosatibialis str.(TCWC 24101, paratype), and M. keaysi str. (MSB 70381). Scale bar $=10 \mathrm{~mm}$

measurements (Tables 5 and 6), with external size larger than M. pilosatibialis str., M. sp. (Quintana Roo, México) and smaller than M. oxyotus gardneri, and $M$. keaysi str. Ears are brown in color, comparatively small to medium-sized (EL $11-14 \mathrm{~mm}$ ). Dorsal and ventral fur is woolly and short (LDF 5.3 -7.4 mm, LVH 4.5-8.3 mm). Dorsal pelage is bicolor, with brown to dark brown at the base and from brown to Mummy Brown at the tips. Ventral pelage is bicolor, with Buckthorn Brown to buff at the tips and dark brown to black at the base. Abdomen is bicolor, from Buckthorn Brown to black with buff tips. Sides and wing color are dark brown or Cinnamon Brown to Mummy Brown. Uropatagium and plagiopatagium are Mummy Brown or Cinnamon Brown. Insertion of the plagiopatagium occurs at the foot at the level of the base of toes by a wide membrane. The uropatagium lacks fringing hairs along the trailing edge. Fur presence on tibia, foot and plagiopatagium, with fur extending across a quarter or less than this at the base of the dorsal and ventral side of uropatagium. Skull and mandible are medium-size (GLS 13.0 -14.0 mm, MAL 8.3-10.3). The dental formula is: $2 / 3,1 / 1,3 / 3,3 / 3=38$. In the holotype, the second upper premolar (p3) is aligned and visible in lateral view. Rostrum is long and frontals are steeply sloping; lambdoidal crest is well developed and occipital region is flattened.

Comparisons. In comparison with species in the ruber group, M. armiensis sp. n. differs from simus and riparius by having a less contrasting dorsal and ventral coloration (dorsal fur with dark brown to Mummy Brown and ventral fur with Buckthorn Brown to dark brown), with more contrasting (Orange-Brown or Chocolate) in simus, (golden -yellow) in midastactus, (ventral hairs with dark brown based and yellowish tips/reddish-brown or cinnamon brown dorsal color) in riparius, (Bister Brown color of dorsal hairs at tips and buff to orange of ventral color at tips) in pilosatibialis

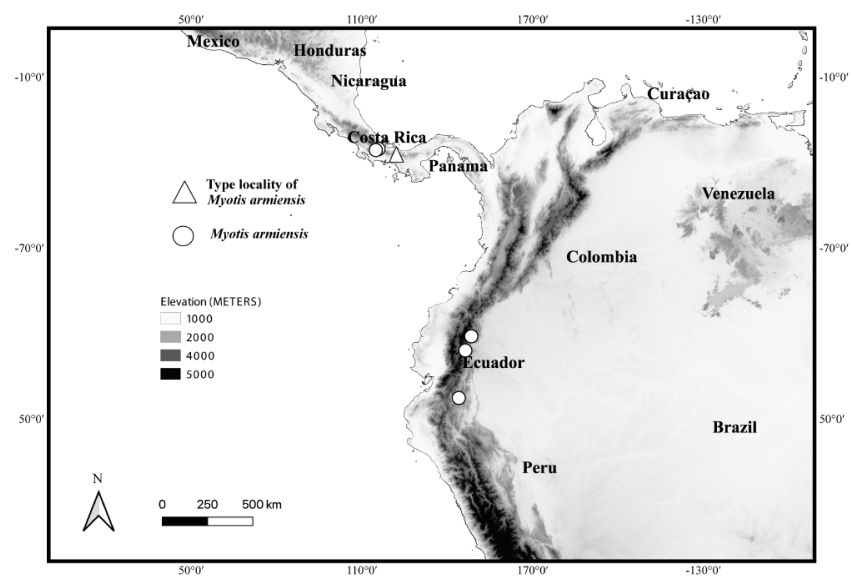

Figure 10. Map of part of Central and South America showing localities examined for M. armiensis, with triangle (type locality) and distribution in Costa Rica, Panamá, and Ecuador with circles. See Appendix I for localities of examined in Panamá and Ecuador.

[type material]. M. armiensis sp. n. can be distinguished from keaysi by having shorter woolly hair on dorsal and ventral side, with longer woolly hair, larger proportion of fur on dorsal and ventral side of the uropatagium, and furrier tibia in keaysi. It differs from simus by having the plagiopatagium attached broadly to the side of the foot at the level of the toes; with a narrow band of membrane $(<1.5$ $\mathrm{mm}$ ) attached to foot or ankles and with extremely short and woolly fur in simus. M. armiensis sp. n. shares the flattened occipital region and a moderate to high sagittal crest with members of the ruber group. It can be distinguished from $M$. ruber by presence of woolly hair, with silky pelage in ruber. Cranial index of $M$. armiensis sp. $\mathrm{n}$. is only larger that M. pilosatibialis str. but smaller than other congeners in the ruber group (CRI: armiensis $=47.0-53.7$, pilosatibialis $=45.8-49.1$, keaysi $=49.7-53.9$; simus $=73.0-88.1$; ruber $=$ 78.4-85.0; riparius $=64.6-76.1$ ), reflecting a narrower skull configuration.

Myotis armiensis sp. n. differs from the albescens group (albescens, handleyi, nesopolus, nigricans, oxyotus oxyotus, oxyotus gardneri, izecksohni, lavali and levis) by having short woolly hair. It only shares the woolly hair trait with chiloensis. In addition, it can be distinguished from albescens group by the presence of a moderate sagittal crest [absent in albescens, very low or absent in oxyotus, absent in nigricans or very low, absent in lavali, very low in chiloensis]. Myotis armiensis sp. $\mathrm{n}$. differs from levis and albescens by the absence of fringe of hairs along the edge of the uropatagium. Occipital region is flattened in M. armiensis sp. $\mathrm{n}$. [rounded in albescens, oxyotus, lavali, nigricans]. The cranial index for albescens group is larger than M. armiensis sp. n, having the narrowest skull configuration in comparison with this species group.

Reproductive data. One pregnant female with one embryo (MSB 262085) collected by Joseph A. Cook and collaborators at Las Nubes Ranger Station, La Amistad International Park, 20 March 2012. Another female (USNM 323599) with embryo (crown-rump $=3 \mathrm{~mm}$ ) collected at Cerro 
Punta, Casa Tiley, Chiriquí Province, collected by Greenwell, F. M, 6 March 1962. In Ecuador, one pregnant female (TTU 85060) with embryo (crown-rump $=3 \mathrm{~mm}$ ) collected by Robert J. Baker and collaborators (Sowell-Expedition, 2001) at Colonia Azuay, Tungurahua Province, 24 July, 2001.

Habitat and ecological notes. Las Nubes Ranger Station, the type locality for this new species, is part of a natural corridor $(401,000 \mathrm{ha})$ of relatively undisturbed montane habitats of the eastern Talamanca Mountains that rise between the Pacific and Caribbean coastlines of Panamá and Costa Rica (Morrone 2017). At La Amistad International Park, Las Nubes Ranger Station, M. armiensis sp. n. was found to occur sympatrically with Desmodus rotundus, Anoura geoffroyi, Sturnira cf. burtonlimi, Sturnira mordax, Enchistenes hartii (Phyllostomidae), and Tadarida brasiliensis (Molossidae). All captures in 2011, 2012 were with ground mist nets located on the edge of secondary growth forest near Las Nubes Rangers Station. Specimens were collected at a clearing on the edge of the forest (Cerro Punta, Casa Tiley) and in montane forest near a lake shore and moist montane secondary growth forest ( 2 miles S. W of El Volcán). We did not record any other species of Myotis living in sympatry at La Amistad International Park, but based on historic samples, the nominal subspecies $M$. oxyotus gardneri was found in sympatry with the new species at Cerro Punta and El Volcán.

At Valle del Silencio Costa Rica, M. armiensis sp. n. was found with Sturnira burtonlimi, Dermanura tolteca, Hylonycteris underwoodi, Anoura cultrata (Phyllostomidae), and Lasiurus blossevillii, Myotis cf. nigricans, and M. oxyotus gardneri (Vespertilionidae). The vegetation there was characterized by the presence of oak trees (Quercus spp) and bamboo (Chusquea spp.), although some sites at Valle del Silencio were dominated by swampy bogs (Chaverri et al. 2016).

In Ecuador, M. armiensis sp. $\mathrm{n}$. is known from premontane and montane cloud forest of Cordillera Oriental. These forests correspond to Evergreen Lower Montane Forest and Cloud Montane Forest (Bosque Siempreverde Montano Bajo and Bosque de Neblina Montano; Valencia et al. 1999). One specimen of $M$. armiensis sp. n. was netted across a trail leading to secondary growth forest in Cabañas del Aliso, Cosanga, Quijos Valle, Napo Province in December, 2017. Other species captured in sympatry at that location were: Sturnira bogotensis, Carollia brevicauda (Phyllostomidae), Tadarida brasiliensis (Molossidae), and M. oxyotus oxyotus and Histiotus montanus (Vespertilionidae). The vegetation there was characterized by the presence of epiphytes (moss, ferns, orchids, bromeliads), bamboo (Chusquea spp.), and pepper plants (Piper spp. and Peperomia spp.). Another specimen of $M$. armiensis sp. $\mathrm{n}$. was captured in Colonia Azuay, Tungurahua Province at the north side of the Río Pastaza. This locality is bisected by the Río Topo, a tributary of the Pastaza river and comprises secondary forest and fruit orchards (Haynie et al. 2006). Other bat species captured in sympatry at that location were: Anoura caudifer, Artibeus lituratus, Carollia perspicillata, and Sturnira erythromus. (Phyllostomidae).
Remarks. It was not possible to examine a set of fluid preserved specimens $(n=43)$ collected at La Amistad International Park Ranger Station, Bugaba District, Chiriquí Province, collected in 2018 by Joseph A. Cook and collaborators (Tropical Biology Class 2018 and Gorgas Institute field workers). Those specimens, until recently housed at the Gorgas Institute in Panama, may represent $M$. armiensis sp. $n$., but confirmation will require further molecular and morphological analysis (MSB 262086 -88, MSB 262219262224, 268090-93, MSB 327505-327516, MSB 327520, MSB 327522 -327527, MSB 327575-578, MSB 327601-602, MSB 327649-50, MSB 327700, MSB 327703, MSB 327705, MSB 327709, MSB 327712, MSB 327956).

Based on this report and other museum collections records, the diversity of Myotis comprises at least six species in Panamá: M. albescens, M. oxyotus gardneri, M. riparius, M. pilosatibialis, M. nigricans s.l., and M. armiensis sp. n. In Ecuador, the recognition of this newly identified lineage, increases the diversity to eight species of Myotis: M. albescens, $M$. riparius, $M$. simus, $M$. oxyotus oxyotus, $M$. diminutus, M. keaysi, M. nigricans s.l., and M. armiensis sp. n. In Costa Rica, Myotis diversity increases to seven species: M. elegans, M. riparius, M. albescens, M. pilosatibialis, M. nigricans s.l., $M$. oxyotus. gardneri and now M. armiensis sp. $\mathrm{n}$.

Nomenclatural statement.- A life science identifier (LSID) number was obtained for new species described herein: urn:Isid:zoobank.org:pub:9EB39E62-C9AC-41C0AE76-9C5325608BEE.

Conservation. Myotis armiensis sp. $\mathrm{n}$. is restricted to higher and cooler mountain forest of Panamá, Costa Rica and Cordillera Oriental (Ecuador). These habitats are susceptible to the effects of climate change, in addition to ongoing habitat destruction. This report aims to contribute to efforts to study these environments and more narrowly add to our understanding of species limits of this elusive group of bats.

\section{Acknowledgments}

We would like to honor S. Anderson for demonstrating throughout his life of fieldwork in mammalogy (extending from Janos, Chihuahua to Tarija, Bolivia) the immense, multifaceted, and lasting value of each voucher specimen to science and society. Likewise, we especially like to thank R. Moratelli for providing access to morphological and morphometric data from Central America and South American Myotis. The completion of this research would have not been possible without his generous offer of this information. We would like to thank also P. A Menendez (McGill University, Canada) for his help with statistical analyses. The following curators and collection managers provided access to specimens under their care: S. Burneo, A. Camacho (Museo de Zoología QCAZ-Pontificia Universidad Católica del Ecuador, Quito-Ecuador); B. Patterson (Field Museum of Natural History, Chicago); E. Lacey, J. Patton, C. Conroy (Museum of Vertebrate Zoology, Berkeley); J. Dunnum and M. Campbell (Museum of Southwestern 
Biology, Albuquerque); R. Bradley, C. D. Philips, and H. Garner (Museum of Texas Tech University, Lubbock); J. K. Braun and B. S. Coyner (Sam Noble Oklahoma Museum of Natural History, Norman); K. Bell (Natural History Museum of Los Angeles County); D. Lunde and A. Gardner (Smithsonian National Museum of Natural History, Washington, D.C.); and J. Light (Biodiversity Research and Teaching Collections, College Station). Although not accessible to the first author, previously, N. Simmons and E. Westwig (American Museum of Natural History) provided specimen access to R. Moratelli and he kindly shared those data. We thank J. Korbin of Sandia National Laboratory for graciously preparing and providing the CT Scans of the skull of the holotype specimen. Support for C. A. Carrión Bonilla was from the Instituto de Fomento al Talento Humano IFTH -Ecuador. Laboratory work in Ecuador was funded by the Secretary de Educación Superior, Ciencia, Tecnología e Innovación del Ecuador SENESCYT (Arca de Noé Initiative, O. Torres and S. Ron, Principal Investigators), and grants from Pontificia Universidad Católica del Ecuador. Field work in Ecuador and Panamá was supported by Latin American Institute's Field Research Grant program at the University of New Mexico and Museum of Southwestern Biology. We would like to thank the personnel of the Gorgas Institute, Panama and the many scientists that collected and preserved specimens of Myotis over many years or that submitted DNA sequences Myotis to GenBank, making them accessible to this study.

\section{Literature cited}

Baud, F. J., ANd H. Menu. 1993. Paraguayan bats of the genus Myotis, with a redefinition of Myotis simus (Thomas, 1901). Revue Suisse de Zoologie 100:595-607.

Baird, A. B., D. M. Hillis, J. C. Patton, and J. W. Bickham. 2008. Evolutionary history of the genus Rhogeessa (Chiroptera: Vespertilionidae) as revealed by mitochondrial DNA sequences. Journal of Mammalogy 89:744-754.

ВесK, M. W. 2017. ggord: Ordination Plots with ggplot2. R Package version 1.0.0.

Bouckaert, R., T. G.Vaughan, J. Barido-Sottanı, S. Duchêne, M. Fourment, A. Gavryushiina, J. Heled, G. Jones, D. Kühnert, N. De Maio, M. Matschiner, F. K Mendes, N. F. Müller, H. A, Ogilvie, l. Du Plessis, A. Popinga, A. Rambau, D. Rasmussen, I. Siveroni, M. A. SucharD, C-H. Wu, D. XIE, C. Zhang, T. StadLer, ANd A. J. Drummonds. 2019. BEAST 2.5: An advanced software platform for Bayesian evolutionary analysis. Plos Computational Biology 15:1-28.

Bickford, D., D. J. Lohman, Navjot. S. S, P. K. L, Ng , R. Meier, K. WinkeR, K. K. Ingram, And I. Das. 2007. Cryptic species as a window on diversity and conservation. Trends in Ecology \& Evolution 22:148-155.

Carøe, C., S. Gopalakrishnan, L. Vinner, S. S. T. Mak, M. H. S. Sinding, J. A. Samaniego, N. Wales, T. Sicheritz-Ponten, and M. T. P. GILBERT. 2018. Single-tube library preparation for degraded DNA, Methods in Ecology and Evolution 9:410-419.

Chaverri, G., I. Garin, A. Alberdi, L. Jimenez, C. Castillo-Salazar, and J. Ainartza. 2016. Unveiling the hidden bat diversity of a neotropical montane forest. Plos one, 11:e0162712.
Clare, E. L., B. K. Lim, M. B. Fenton, and P. D. N. Hebert. 2011. Neotropical Bats: Estimating Species Diversity with DNA Barcodes. Plos One 6:1-14.

De Queiroz, K. 2007. Species Concepts and Species Delimitation. Systematic Biology 56:879 - 886.

Dierckxsens, N., P. Mardulyn, AND G. Smits. 2016. NOVOPlasty: de novo assembly of organelle genomes from whole genome data. Nucleic Acids Research 45:1-9.

Dunnum, J. L., B. S, Mclean, R. C. Dowler, and The Systematic Collections Committee of the American Society of Mammalogist. 2018. Mammal collections of the Western Hemisphere: a survey and directory of collections. Journal of Mammalogy 99:1307-1322.

EdGAR, R. C. 2004. MUSCLE: multiple sequence alignment with high accuracy and high throughput. Nucleic Acids Research 32:1792-1797.

Eick, G. N., D. S. Jacobs, and C. A. MattheE. 2005. A nuclear DNA phylogenetic perspective on the evolution of echolocation and historical biogeography of extant bats (Chiroptera). Molecular Biology and Evolution 22:1869-1886.

Fick, S. E., AND R. J, Hımans. 2017. WorldClim2: new $1 \mathrm{~km}$ spatial resolution climate surface for global land areas. International Journal of Climatology 37:4302-4315.

Florio, A. M., C. M. Ingram, H. A. Rakotondranovy, E. E. Louis, C. J. Raxworthy. 2012. Detecting cryptic speciation in the widespread and morphologically conservative carpet chamelon (Furcifer lateralis) of Madagascar. Journal of Evolutionary Biology 25:1399-1414.

FLot, J. F. 2010. SEQPHASE: a web tool for interconverting phase input/output files and fasta sequence alignments. Molecular Ecology Resources 10:162-166.

Fox, J., AND S. WeIsBerg. 2019. An R Companion to Applied Regression. Third edition. Sage, Thousands Oaks CA.

Galbreath, K. E., E. P. Hoberg, J. A. Cook, B. Armién, K. C. Bell, M. L. Campbell, J. Dunnum, A. T. Dursahinhan, R. P. Eckerlin, S. L. Gardner, S. E. Greiman, H. Henttonen, F. A. Jiménez, A. VA. Koehler, B. Nyamsuren, V. V. Tkach, F.Torres-Pérez, A.Tsvetkova ,AND A. HopE. 2019. Building an integrated infrastructure for exploring biodiversity: field collections and archives of mammals and parasites. Journal of Mammalogy 100:382-393.

Haynie, M. L., J. G. Brant, L. R. McAllley, J. P. Carrera, M. A, Revelez, D. A, Parish, X. Viterl, C. Jones, and C. J. Phillips. 2006. Investigations in a Natural Corridor between two national parks in Central Ecuador: Results from the Sowell Expedition, 2001. Occasional Papers, Museum of Texas Tech University 263:1-16.

Heled, J., AND A. J. Drummond. 2010. Bayesian Inference of Species Trees from Multilocus Data. Molecular Biology and Evolution 27:570-580.

Hernandez-Meza, B., Y. Dominguez-Castellanos, and J. Ortega. 2005. Myotis keaysi. Mammalian Species 785:1-3.

Hoffmann, F. G., AND R. J. Baker. 2001. Systematics of bats of the genus Glossophaga (Chiroptera: Phyllostomidae) and phylogeography in G. soricina based on the cytochrome-b gene. Journal of Mammalogy 82:1092-1101.

Honaker, J., G. KING, AND M. BLACKWELl. 2011. Amelia II: A Program for Missing Data. Journal of Statistical Software 45:1-47.

Jones, G. 2017. Algorithmic improvements to species delimitation and phylogeny estimation under the multispecies coalescent. Journal of Mathematica Biology 74:447-467. 
Jones, G. speciesDA.jar. htpp://indriid.com/2014/speciesDA. jar. Accessed 15 July 2020.

Kalyanamoorthy, S., B. Q. Minh, T. K. F. Wong, A. von Haeseler, AND L. S. JERMIIN. 2017. ModelFinder: fast model selection for accurate phylogenetic estimates. Nature Methods 14:587-591.

Kassambara, A. 2020. Rstatix: Pipe-Friendly Framework for Basic Statistical Test. R package version 0.6.0.

Kassambara, A., And F. Mundt. 2020. factoextra: Extract and Visualize the Results of Multivariate Data Analyses. R package version 1.0.7.999.

Kawal, K., N. Kondo, N. Sasaki, D. Fukul, H. Dewa, M. Sato, and Y.yamagal. 2006. Distinguishing between cryptic species Myotis ikonnikovi and M. brandtii gracilis in Hokkaido, Japan: Evaluation of a novel diagnostic morphological feature using molecular methods. Acta Chiropterologica 8:95-102.

Kawal, K., M. Nikaido, Harada, S. Matsumura, L-K, Lin, Y.Wu, M. Hasegawa, AND N. OKada. 2003. The status of the Japanese and East Asian bats of the genus Myotis (Vespertillonidae) based on mitochondrial sequences. Molecular Phylogenetics and Evolution 28:297-307.

Koopman, K. F. 1983. Two general problems involved in systematics and zoogeography of bats. Pp. 412-415 in Advances in herpetology and evolutionary biology. Essays in honor of Ernest E Williams (Rhodin, G. J., and K. Miyata, eds). Museum of Comparative Zoology, Cambridge, Massachusetts, EE.UU.

Kumar, S., G. Stecher, and K. Tamura. 2016. MEGA7: Molecular Evolutionary Genetics Analysis Version 7.0 for Bigger Datasets. Molecular Biology and Evolution 33:1870-1874.

LA VAL, R. K. 1973. A revision of Neotropical bats of the genus Myotis. Natural History Museum of Los Angeles County. Science Bulletin:1-54.

Lack, J. B., Z. P. Roehrs, C. E. Stanley, M. Rued, and R. A. Van den Bussche. 2010. Molecular phylogenetics of Myotis indicate familial-level divergence for the genus Cistugo (Chiroptera). Journal of Mammalogy 91:976-992.

Larsen, R. J., M. C. Knapp, H. H. Genoways, F. A Anwarali Khan, P. LaRsen, D.Wilson, and R. J. Baker. 2012a. Genetic Diversity of Neotropical Myotis (Chiroptera: Vespertilionidae) with an Emphasis on South American Species. Plos One 7:1-9.

Larsen, R. J., P. Larsen, H. H. Genoways, F. M. Catzeflis, K. Gelusos, G.G Kwiecinski, S. C. Pedersen, F. Simal, and R. J. Baker. 2012b. Evolutionary history of Caribbean species of Myotis, with evidence of a third Lesser Antillean endemic. Mammalian Biology 77:124-134.

LINDGREEN, S. 2012. AdapterRemoval: easy cleaning of nextgeneration sequencing reads. BMC Research Notes 5:337-337.

López -González, C., S. J. Presley, R. D. Owen, M.R. Willig. 2001. Taxonomic status of Myotis (Chiroptera: Vespertilionidae) in Paraguay. Journal of Mammalogy 82:138-160.

Mak, S. S. T., S. Gopalakrishnan, C. Carøe, C. Geng, S. LiU, M. H. S. Sinding, L. F. K. Kuderna, W. Zhang, S. Fu, F. G. Vieira, M. Germonpre, H. Bocherens, S. Fedorov, B. Petersen, T. SicheritzPonten, T. Marques-Bonet, G. Zhang, H. Jiang, and M.T.P. GilBERT. 2017. Comparative performance of the BGISEQ-500 vs Illumina HiSeq2500 sequencing platforms for palaeogenomic sequencing. Gigascience 6:1-13.

Mammal Diversity Database. 2020. www.mammal.diversity.org. American Society of Mammalogist. Accessed 2020-04-19.
Mantilla-Meluk, H., and J. Munoz-Garay. 2014. Biogeography and taxonomic status of Myotis keaysi pilosatibialis LaVal 1973 (Chiroptera: Vespertilionidae). Zootaxa 3793:60-70.

Matthee, C. A., and S. K. Davis. 2001. Molecular insights into the evolution of the family Bovidae: A nuclear DNA perspective. Molecular Biology and Evolution 18:1220-1230.

McLean, B. S., D. J, JACKson, AND J. A. Cook. 2016. Rapid divergence and gene flow at high latitudes shape the history of Holarctic ground squirrels (Urocitellus). Molecular Phylogenetics and Evolution 102:174-188.

MenG, G., Y. LI, C. YanG, ANd S. Liu. 2019 MitoZ: a toolkit for animal mitochondrial genome assembly, annotation and visualization. Nucleic Acids Research 47:1-7.

Moratell, R., AND Wilson, D. 2011. A new species of Myotis Kaup, 1829 (Chiroptera: Vespertilionidae) from Ecuador. Mammalian Biology 76:608-614.

Moratelli, R., A. L. Gardner, J. A. De Oliveira, and D. E. Wilson. 2013. Review of Myotis (Chiroptera, Vespertilionidae) from northern South America, including description of a new species. American Museum Novitates:1-36.

Moratell, R., And D. E. Wilson. 2014. A new species of Myotis (Chiroptera, Vespertilionidae) from Bolivia. Journal of Mammalogy 95:17-25.

Moratell, R., D. E. Wilson, A. L. Gardner, R. D. Fisher, and E. E. GutierRez. 2016. A New Species of Myotis (Chiroptera: Vespertilionidae) from Suriname. Pp 49-66 in Contributions in Natural History: A memorial Volume in Honor of Clyde Jones (Manning, R, Goetze, J.R and Yancey II, F.D). Special Publications No 65, Museum of Texas Tech University, Lubbock, EE.UU.

Moratelli, R., D. E. Wilson, R. L. M. Novaes, K. M. Helgen, and E. E. Gutierrez. 2017. Caribbean Myotis (Chiroptera, Vespertilionidae), with description of a new species from Trinidad and Tobago. Journal of Mammalogy 98:994-1008.

Morrone, J. J. 2017. Neotropical Biogeography: Regionalization and Evolution. CRC Press Taylor \& Francis Group, Boca Raton, FL, EE.UU.

Naidu, A., R. R. Fitak, A. Munguia-Vega, and M. Culver. 2012. Novel primers for complete mitochondrial cytochrome $b$ gene sequencing in mammals. Molecular Ecology Resources 12:191-196.

Nguyen, L. T., H. A. Schmidt, A. von Haeseler, and B. Q. Minh. 2015. IQ-TREE: A Fast and Effective Stochastic Algorithm for Estimating Maximum-Likelihood Phylogenies. Molecular Biology and Evolution 32:268-274.

Patterson, B. D., P. W. Webala, J. C. K. Peterhans, S. M. Goodman, M. Bartonjo, AND T. C. Demos. 2019. Genetic variation and relationships among Afrotropical species of Myotis (Chiroptera: Vespertilionidae). Journal of Mammalogy 100:1130-1143.

Queiroz DE, K. 2007. Species Concepts and Species Delimitation. Systematic Biology 56:879-886.

R Core Team. 2020. R: A language and environment for statistical computing. R Foundation for Statistical Computing, Vienna, Austria. URL http://www.R-project.org/.

Rambaut, A., A. J. Drummond, D. Xie, G. Baele, and M. A. Suchard. 2018. Posterior Summarization in Bayesian Phylogenetics Using Tracer 1.7. Systematic Biology 67:901-904.

Revelle, W. 2020. Psych: Procedures for Psychological, Psychometric, and Personality Research. Northwestern University, Evanston, Illinois. R package version 2.0.7. 
RIDGWAY, R. 1912. Color standards and color nomenclature. Available at Biodiversity Heritage Library (www.biodiversitylibrary.org).

RıcE, W. R. 1989. Analyzing tables of statistical test. Evolution 43:223-225. 01-904.

Rodriguez, R. M., AND L. K. Ammerman. 2004. Mitochondrial DNA divergence does not reflect morphological difference between Myotis californicus and Myotis ciliolabrum. Journal of Mammalogy 85:842-851.

Roehrs, Z. P., J. B. Lack, And R. A. Van den Bussche. 2010. Tribal phylogenetic relationships within Vespertilioninae (Chiroptera: Vespertilionidae) based on mitochondrial and nuclear sequence data. Journal of Mammalogy 91:1073-1092.

Ronquist, F., M. Teslenko, P.VAn der Mark, D.L, Ayres, A. Darling, S. Höhna, B. Larget, L. Liu, M. A, Suchard, and J. Huelsenbeck. 2012. MrBayes 3.2: Efficient Bayesian Phylogenetic Inference and Model Choice Across a Large Model Space. Systematic Biology 61:539-542.

Ruedi, M., ANd F. Mayer. 2001. Molecular systematics of bats of the genus Myotis (vespertilionidae) suggests deterministic ecomorphological convergences. Molecular Phylogenetics and Evolution 21:436-448.

Ruedi, M., B. Stadelmann, Y. Gager, E. J. P. Dourezy, C. M. Francis, L-K. Lin, A. Guillén-Servent, And A. Cibois . 2013. Molecular phylogenetic reconstructions identify East Asia as the cradle for the evolution of the cosmopolitan genus Myotis (Mammalia, Chiroptera). Molecular Phylogenetics and Evolution 69:437-449.

Salicini, I., C. Ibanez, and J. Juste. 2011. Multilocus phylogeny and species delimitation within the Natterer's bat species complex in the Western Palearctic. Molecular Phylogenetics and Evolution 61:888-898.

Schubert, M., S. Lindgreen, And L. Orlando. 2016. AdapterRemoval v2: rapid adapter trimming, identification, and read merging. BMC Research Notes 9:88-88.

Sikes, R. S., And M. Anim Care Use Comm Amer Soc. 2016. Guidelines of the American Society of Mammalogists for the use of wild mammals in research and education. Journal of Mammalogy 97:663-688.

Swofford, D. L. (2003). PAUP*. Phylogentic analysis using parsimony (* and other methods). Version 4.0a168. Sinauer Associates, Sunderland.

Stadelmann, B., L. G. Herrera, J. Arroyo-Cabrales, J. J. FloresMartinez, B. P. MaY, And M. Ruedi. 2004. Molecular systematics of the fishing bat Myotis (Pizonyx) vivesi. Journal of Mammalogy 85:133-139.

Stadelmann, B., L. K. Lin, T. H. Kunz, and M. Ruedi. 2007. Molecular phylogeny of New World Myotis (Chiroptera, Vespertilionidae) inferred from mitochondrial and nuclear DNA genes. Molecular Phylogenetics and Evolution 43:32-48.

Stephens, M., N. J. Smith, And P. Donnelly. 2001. A new statistical method for haplotype reconstruction from population data. American Journal of Human Genetics 68:978-989.

Trifinopoulos, J., L. T. Nguyen, A. von Haeseler, and B. Q. Minh. 2016. W-IQ-TREE: a fast online phylogenetic tool for maximum likelihood analysis. Nucleic Acids Research 44:232-235.

Venables, W. N., And Ripley, B. D. 2002. Modern Applied Statistics with S. Springer, New York, EE.UU.

Valencia, R., C. Cerón, W. Palacios, and R. Sierra. 1999. Las formaciones naturales de la Sierra del Ecuador. Pp. 79-108 in
Propuesta Clasificación de Vegetación para el Ecuador Contiental (Sierra, R., eds.). Quito, Ecuador: Proyecto INEFAN/GEFBIRF and EcoCiencia.

Voss, R. S., B. K. Lim, J. F. Diaz -Nieto, And S. A. Jansa. 2013. A New Species of Marmosops (Marsupialia: Didelphidae) from the Pakaraima Highlands of Guyana, with Remarks on the Origin of the Endemics Pantepui Mammal Fauna. American Museum Novitates 3778:1-27.

Wıскнам, H. 2016. ggplot2: Elegant Graphics for Data Anlyses. Springer-Verlag, New York, EE.UU.

Wilson, D. E. 2008. [2007]. Genus Myotis. Pp. 468-481 in Mammals of South America, Volume I Marsupials, Xenarthrans, Shrews and Bats (Gardner, A.L, ed). The University of Chicago Press, Chicago, EE.UU.

ZAR, J. H. 1998. Biostatistical analysis (4th ed). Upper Saddle River, NJ: Prentice Hall.

Associated editor: Jorge Salazar-Bravo

Submitted: April 20, 2020; Reviewed: June 23, 2020;

Accepted:September 20, 2020; Published on line: September 30, 2020. 
Appendix 1. Specimens examined in morphological and morphometric analysis. Specimens are organized according to taxa herein recognized. These vouchers consist of fluid preserved specimens, stuffed skins, and skulls deposited in the following institutions: American Museum of Natural History (AMNH); Field Museum of Natural History (FMNH); Natural History Museum, University of Kansas (KU); Natural History Museum of Los Angeles County, Los Angeles, (LACM); Louisiana State University Museum of Natural Science, Baton Rouge (LSUMZ); Museum of Vertebrate Zoology, University of California, Berkeley (MVZ); Museum of Southwestern Biology, University of New Mexico (MSB); National Museum of Natural History, Smithsonian Institution (USNM); Museo de Zoología, División de Mastozoología, Pontificia Universidad Católica del Ecuador (QCAZ), Royal Ontario Museum (ROM); Sam Noble Oklahoma Museum of Natural History, University of Oklahoma (SNOMNH); Texas A\&M Biodiversity Research and Teaching Collection, College Station (TCWC); Museum of Texas Tech University (TTU). Localities are arranged alphabetically by species and major political units. Specimens marked with asterisks were included in the principal component and discriminant analyses.

Myotis albescens. ARGENTINA ( $n=1)$ : Tucumán, Trancas, km 42 on Hwy 364, S San Pedro de Colalao (SNOMNH 23790). PERU ( $n=7)$ : Uyacali, Balta, Río Curanja (MSB 28518-24).

Myotis armiensis sp. n. PANAMA ( $n=16)$ : Chiriquí, Bugaba, La Amistad International Park, Rangers Station (MSB 262089* [holotype], MSB 262085, MSB 262237 [paratypes]); Chiriquí, Bugaba, Renacimiento, Jurutungo, Río Sereno, La Amistad International Park (MSB 262788 [paratype]), Chiriquí, Renacimiento, Santa Clara (TTU 39146 [paratype]), Chiriquí, Renacimiento, Santa Clara, Ojo de Agua, 2 km N of Santa Clara (ROM 104302 [paratype]), Chiriquí, Tierras Altas, Cerro Punta, Casa Tiley (USNM 323599* [paratype]), Chiriquí, Tierras Altas, El Volcán 2 min SW (USNM 331942*, USNM 331943* [paratypes]), Chiriquí, Bugaba, 36 Km, North of Concepción (TCWC 1265559* [paratypes]); ECUADOR $(n=3)$ : Tungurahua Province, Azuay (TTU 85060 [paratype]), Napo Province, Cosanga, Cabañas del Aliso (QCAZ 17245 [paratype]), Zamora Chinchipe, Yantzaza, Campo Minero Fruta del Norte (QCAZ 12461[paratype]).

Myotis chiloensis. ARGENTINA $(n=1): 19 \mathrm{~km} \mathrm{~N}$ Villa La Angostura along Hwy 234 (SNOMNH 23496).

Myotis diminutus. ECUADOR $(n=1)$ : Los Ríos, Rio Palenque Science Center. 47 km S (by road) of Santo Domingo de los Colorados (USNM 528569 [holotype]).

Myotis dinellii. ARGENTINA $(n=2)$ : Salta, Guachipas, 7.8 km NNE Pampa Grande along Ruta Provincial 6 along Rio Cachi (SNOMNH 27933), Chubut, 3 km N Tecka along Hwy 40 (SNOMNH 23497).

Myotis keaysi. BOLIVIA ( $n=1)$ : Cochabamba Jachá Suyu (MSB 70381); PERU $(n=5)$ : Puno Ocaneque, $10 \mathrm{mi} N$ Limbani (MVZ 116050*); Cuzco, Cordillera Vilcabamba (AMNH 236134*, $\left.233857^{*}, 233854^{*}, 214371^{*}\right)$.

Myotis levis. BRASIL $(n=1)$ : Sao Paulo, Estación Biológica Boraceia (FMNH 145327).
Myotis nigricans. BRASIL $(n=3)$ km 42 Antigua Rodavia RíoSao Paulo. Iguatari Municipality, Rio de Janeiro (TCWC 2281113 [neotypes]).

Myotis oxyotus oxyotus. ECUADOR $(n=3)$ : Carchi, Gruta Rumichaca, 2 mi E La Paz (TCWC 12703-04, TCWC 12706 [neotypes]). PERU $(n=4)$ Huánuco, $10 \mathrm{Km} \mathrm{N}$. Acomayo Bosque Unchog (MSB 49971-72); Huánuco 9 min S Huánuco (TCWC 12710-11).

Myotis oxyotus gardneri. COSTA RICA $(n=3)$ San José, Fila la Máquina (LSUMZ 12924* [holotype], 12917*,12929*). PANAMA $(n=3)$ Cerro Punta (USNM 318386*), Finca Lara (USNM 318869*, 318870*).

Myotis pilosatibialis. EL SALVADOR $(n=6)$ Ahuachapán, El Imposible, San Francisco Méndez (ROM 101273*), Santa Ana, Parque Nacional Montecristo, Bosque Nebuloso (ROM 101352*, 101357*, 101430*), Santa Ana, Parque Nacional Montecristo, Los Planes (ROM 101467*), Santa Ana, Hacienda Escuintla (TTU 60981*). HONDURAS ( $n=7)$ : Francisco Morazán, $1 \mathrm{~km}$ W of Talanga (LACM 36879* [holotype], TCWC 24101-24105 [paratypes]); Cortés, Omoa, $5.5 \mathrm{~km}$ southeast of Cuyamel, Santo Domingo (AMNH 265126). GUATEMALA (3): Petén Department, 12 km of Chinaja (KU 82105, 82108, 82109). MEXICO ( $n=1)$ : San Luis Potosí (TTU 35360*).

Myotis riparius. BOLIVIA $(n=1)$ : Cochabamba, Sajta (MSB 70383); ARGENTINA ( $n=1)$ : Tucumán, Tafí Viejo. 5 km S.W. Siambon (SNOMNH 36220). ECUADOR $(n=1)$ : Esmeraldas, Comuna San Francisco de Bogotá (TTU 102833). PARAGUAY ( $n$ = 1): Department of Canindeyu, Reserva Natural Privada Itabo (TTU 99378).

Myotis sp. MEXICO $(n=4)$ Yucatán Peninsula, Quintana Roo, Pueblo Nuevo (KU 91911*, KU 91912*, KU 91915*, KU 91916*). 
Appendix 2. List of specimens used in cytochrome-b analyses of Neotropical Myotis. Specimens details, localities, and Genbank accession numbers of sampled individuals of Neotropical Myotis. Carnegie Museum of Natural History (CM); France (Catzeflis-Montpellier-V-); Field Museum of Natural History (FMNH); Jean-François Maillard (JFM DIREN); Kunico Kawai (KK); Museum National Histoire Naturelle (MNHN); The Angeles County Museum of Natural History (LACM); Museum of Vertebrate, Zoology, University of California Berkeley (MVZ); Museum of Southwestern Biology, The University of New Mexico (MSB); National Museum Prague (NMP); Osaka City University Graduate School of Medicine (OCUMS); Museo de Zoología de la Pontificia Universidad Católica del Ecuador (QCAZ); T.H. Kunz (THK); Museum of Texas Tech University (TTU and TK); Universidad Autónoma Metropolitana-Iztapalapa (UAMI); University of Nebraska State Museum (UNSM).

\begin{tabular}{|c|c|c|c|c|c|c|c|c|}
\hline Institution & Cat. No. & Species & GenBank & Country & Locality & Latitude & Longitude & Source \\
\hline CM & 63920 & Myotis albescens & $J X 130444$ & Suriname & Nickerie & 5.63 & -56.79 & Larsen et al. (2012a) \\
\hline TTU & 85088 & Myotis albescens & $J X 130463$ & Ecuador & Pastaza & -1.44 & -77.99 & Larsen et al. (2012a) \\
\hline TTU & 85089 & Myotis albescens & $J X 130464$ & Ecuador & Pastaza & -1.44 & -77.99 & Larsen et al. (2012a) \\
\hline TTU & 102363 & Myotis albescens & $J X 130472$ & Ecuador & El Oro & -3.51 & -80.13 & Larsen et al. (2012a) \\
\hline TTU & 102348 & Myotis albescens & $J X 130500$ & Ecuador & El Oro & -3.51 & -80.13 & Larsen et al. (2012a) \\
\hline TTU & 103744 & Myotis albescens & $J X 130501$ & Ecuador & Guayas & -2.45 & -79.62 & Larsen et al. (2012a) \\
\hline TK & 151814 & Myotis albescens & JK130586 & Ecuador & Zamora-Chinchipe & --- & --- & Larsen et al. (2012a) \\
\hline FMNH & 162543 & Myotis albescens & AF376839 & Bolivia & Tarija & -21.78 & -64.09 & Ruedi and Mayer (2001) \\
\hline FMNH & 174926 & Myotis albescens & MK799657 & Perú & Maskoitania & -12.77 & -71.38 & Patterson et al. (2019) \\
\hline TTU & 46343 & Myotis albescens & $J X 130445$ & Perú & Huánuco & -09.18 & -75.59 & Larsen et al. (2012a) \\
\hline TTU & 99124 & Myotis albescens & $J X 130503$ & Paraguay & Boquerón & -21.73 & -60.95 & Larsen et al. (2012a) \\
\hline TTU & 99801 & Myotis albescens & $J X 130502$ & Paraguay & Ñeembucú & -27.04 & -57.86 & Larsen et al. (2012a) \\
\hline TTU & 99818 & Myotis albescens & $J X 130504$ & Paraguay & Ñeembucú & -27.04 & -57.86 & Larsen et al. (2012a) \\
\hline MSB & 262089 & Myotis armiensis sp. $\mathrm{n}$. & MW025265 & Panamá & Chiriquí & 8.89 & -82.61 & This study \\
\hline MSB & 262237 & Myotis armiensis sp. $\mathrm{n}$. & MW025266 & Panamá & Chiriquí & 8.89 & -82.61 & This study \\
\hline MSB & 262085 & Myotis armiensis sp. $\mathrm{n}$. & MW025268 & Panamá & Chiriquí & 8.89 & -82.61 & This study \\
\hline MSB & 262788 & Myotis armiensis sp. $\mathrm{n}$. & MW025267 & Panamá & Chiriquí & 8.89 & -82.61 & This study \\
\hline TTU & 39146 & Myotis armiensis sp. $\mathrm{n}$. & JX130435 & Panamá & Chiriquí & --- & --- & Larsen et al. (2012a) \\
\hline QCAZ & 12461 & Myotis armiensis sp. $\mathrm{n}$. & MW025274 & Ecuador & Zamora Chinchipe & -3.75 & -78.53 & This study \\
\hline QCAZ & 17245 & Myotis armiensis sp. $\mathrm{n}$. & MW025269 & Ecuador & Napo & -0.62 & -77.90 & This study \\
\hline TTU & 85060 & Myotis armiensis sp. $\mathrm{n}$. & $J X 130514$ & Ecuador & Tungurahua & -1.34 & -78.20 & Larsen et al. (2012a) \\
\hline MVZ & 168933 & Myotis atacamensis & AM261882 & Perú & Olmos & -5.84 & -79.82 & Ruedi and Mayer (2001) \\
\hline USNM ZM & 29470 & Myotis attenboroughi & JN020573 & Tobago & St. George Parish & 11.32 & -60.55 & Larsen et al. (2012b) \\
\hline THK & 002 & Myotis austroriparius & AM261885 & United States & Tennessee & 35.51 & -86.58 & Stadelmann et al. (2007) \\
\hline THK & 1 & Myotis chiloensis & AM261888 & Chile & Santiago de Chile & -33.44 & -70.66 & Stadelmann et al. (2007) \\
\hline TTU & 109227 & Myotis clydejonesi & $J X 130520$ & Suriname & Sipaliwini & 4.43 & 56.12 & Larsen et al. (2012a) \\
\hline $\begin{array}{l}\text { UAMI -TK (R. Lopez- } \\
\text { Wilchis) }\end{array}$ & 45364 & Myotis fortidens & $J X 130439$ & México & Michoacán & --- & --- & Larsen et al. (2012a) \\
\hline $\begin{array}{l}\text { UAMI -TK (R. Lopez- } \\
\text { Wilchis) }\end{array}$ & 43134 & Myotis fortidens & $J X 130437$ & México & Michoacán & ---- & --- & Larsen et al. (2012a) \\
\hline LACM & $\begin{array}{l}3713 / \\
\text { LAF0030 }\end{array}$ & Myotis fortidens & KC747690 & México & Guerrero & ---- & --- & Patrick \& Stevens (2014) \\
\hline THK & 11500 & Myotis grisescens & AM261892 & USA & Tennessee & 35.51 & -86.58 & Stadelmann et al. (2007) \\
\hline TTU & 48161 & Myotis cf. handleyi & JN020569 & Venezuela & Guárico & 8.56 & -67.57 & Larsen et al. (2012b) \\
\hline TTU & 48170 & Myotis cf. handleyi & $J X 130544$ & Venezuela & Guárico & 8.56 & -67.57 & Larsen et al. (2012a) \\
\hline TTU & 48163 & Myotis cf. handleyi & JX130531 & Venezuela & Guárico & 8.56 & -67.57 & Larsen et al. (2012a) \\
\hline TTU & 48164 & Myotis cf. handleyi & $J X 130532$ & Venezuela & Guárico & 8.56 & -67.57 & Larsen et al. (2012a) \\
\hline TTU & 48168 & Myotis cf. handleyi & JX130533 & Venezuela & Guárico & 8.56 & -67.57 & Larsen et al. (2012a) \\
\hline CM & 78645 & Myotis cf. handleyi & $J X 130535$ & Venezuela & Guárico & ---- & --- & Larsen et al. (2012a) \\
\hline TTU & 48169 & Myotis cf. handleyi & $J X 130543$ & Venezuela & Guárico & 8.56 & -67.57 & Larsen et al. (2012a) \\
\hline TTU & 48166 & Myotis cf. handleyi & $J X 130494$ & Venezuela & Guárico & 8.56 & -67.57 & Larsen et al. (2012a) \\
\hline QCAZ & 11383 & Myotis keaysi & $J X 130517$ & Ecuador & Chimborazo & --- & --- & Larsen et al. (2012a) \\
\hline QCAZ & 11380 & Myotis keaysi & $J X 130516$ & Ecuador & Chimborazo & ---- & --- & Larsen et al. (2012a) \\
\hline MSB & 70381 & Myotis keaysi & MW025273 & Bolivia & Cochabamba & -17.21 & -65.86 & This study \\
\hline MVZ & 185681 & Myotis lavali & AF376864 & Brazil & Paraiba & -7.11 & -34.86 & Ruedi and Mayer (2001) \\
\hline
\end{tabular}




\begin{tabular}{|c|c|c|c|c|c|c|c|c|}
\hline FMNH & 141600 & Myotis levis & AF376853 & Brazil & São Paulo & -23.53 & -45.84 & Ruedi and Mayer (2001) \\
\hline MNHN & $2005-895$ & Myotis martiniquensis & JN020557 & Martinique, France & $\begin{array}{l}\text { Grand'Rivière, Mar- } \\
\text { tinique }\end{array}$ & -14.87 & -61.17 & Larsen et al. (2012b) \\
\hline V & 2352 & Myotis martiniquensis & JN020559 & Martinique, France & $\begin{array}{l}\text { Grand' Rivière, Mar- } \\
\text { tinique }\end{array}$ & -14.87 & -61.17 & Larsen et al. (2012b) \\
\hline MNHN & $2008-974$ & Myotis martiniquensis & JN020560 & Martinique, France & $\begin{array}{l}\text { Grand' Rivière, Mar- } \\
\text { tinique }\end{array}$ & -14.87 & -61.17 & Larsen et al. (2012b) \\
\hline V & 2354 & Myotis martiniquensis & JN020561 & Martinique, France & $\begin{array}{l}\text { Grand' Rivière, Mar- } \\
\text { tinique }\end{array}$ & -14.872 & -61.17 & Larsen et al. (2012b) \\
\hline JFM & DIREN 2 & Myotis martiniquensis & AM262332 & Martinique France & --- & --- & $-\ldots$ & Stadelmann et al. (2007) \\
\hline CM & 98859 & Myotis cf. nigricans & $J X 130453$ & Perú & Huánuco & ---- & --- & Larsen et al. (2012a) \\
\hline CM & 77691 & Myotis cf. nigricans & $J X 130497$ & Suriname & Marowijne & --- & $-\ldots$ & Larsen et al. (2012a) \\
\hline No voucher & ---- & Myotis nesopolus & JN20575 & $\begin{array}{l}\text { Netherlands, } \\
\text { Antilles }\end{array}$ & Bonaire & 12.201 & -68.26 & Larsen et al. (2012b) \\
\hline No voucher & ----- & Myotis nesopolus & JN20577 & $\begin{array}{l}\text { Netherlands, } \\
\text { Antilles }\end{array}$ & Bonaire & 12.201 & -68.26 & Larsen et al. (2012b) \\
\hline CM & 83427 & Myotis nyctor & JN020562 & Grenada & St. David Parish & --- & --- & Larsen et al. (2012b) \\
\hline TTU & 109225 & Myotis nyctor & JN020563 & Barbados & St. Thomas Parish & 13.19 & -59.57 & Larsen et al. (2012b) \\
\hline TTU & 109229 & Myotis nyctor & JN020565 & Barbados & St. Thomas Parish & 13.20 & -59.53 & Larsen et al. (2012b) \\
\hline TTU & 109230 & Myotis nyctor & JN020567 & Barbados & St. Thomas Parish & 13.14 & -59.60 & Larsen et al. (2012b) \\
\hline FMNH & 129208 & Myotis oxyotus & AF376865 & Perú & Lima & --- & --- & Ruedi and Mayer (2001) \\
\hline TTU & 35360 & Myotis pilosatibialis & $J X 130526$ & México & San Luis Potosí & 22.00 & -99.00 & Larsen et al. (2012a) \\
\hline TTU & 35631 & Myotis pilosatibialis & $J X 130518$ & México & San Luis Potosí & 22.00 & -99.00 & Larsen et al. (2012a) \\
\hline TTU & 60981 & Myotis pilosatibialis & JX130519 & San Salvador & Santa Ana & 13.46 & -88.88 & Larsen et al. (2012a) \\
\hline MVZ & 226976 & Myotis pilosatibialis & MW025271 & Guatemala & Alta Verapaz & 15.61 & -90.27 & This study \\
\hline MVZ & 226973 & Myotis pilosatibialis & MW025272 & Guatemala & El Quiche & 15.46 & -90.78 & This study \\
\hline MVZ & 224798 & Myotis pilosatibialis & MW025275 & Guatemala & Quetzaltenango & 14.74 & -91.47 & This study \\
\hline MVZ & AD199 & Myotis riparius & AF376866 & Brazil & Pernambuco & ---- & --- & Ruedi and Mayer (2001) \\
\hline CM & 78651 & Myotis riparius & $J \times 130490$ & Venezuela & --- & --- & --- & Larsen et al. (2012a) \\
\hline CM & 78659 & Myotis riparius & $J X 130474$ & Venezuela & Bolívar & ---- & --- & Larsen et al. (2012a) \\
\hline TTU & 99378 & Myotis riparius & JX130491 & Paraguay & Canindeyú, Paraguarí & -24.46 & -54.66 & Larsen et al. (2012a) \\
\hline CM & 68443 & Myotis riparius & JX130473 & Suriname & Paramaribo & --- & --- & Larsen et al. (2012a) \\
\hline Voucher 3011 & ---- & Myotis cf. riparius & AM261891 & Costa Rica & La Selva & ---- & --- & Stadelmann et al. (2007) \\
\hline TTU & 85344 & Myotis riparius & $J X 130469$ & Ecuador & Esmeraldas & 1.23 & -78.76 & Larsen et al. (2012a) \\
\hline TTU & 85345 & Myotis riparius & JX130515 & Ecuador & Esmeraldas & 1.23 & -78.76 & Larsen et al. (2012a) \\
\hline TTU & 102883 & Myotis riparius & $J X 130492$ & Ecuador & Esmeraldas & 1.09 & -78.70 & Larsen et al. (2012a) \\
\hline TK & 22703 & Myotis riparius & $J \times 130436$ & Perú & Huánuco & ---- & --- & Larsen et al. (2012a) \\
\hline THKMys & ET3 & Myotis riparius & AM262336 & Brazil & --- & --- & --- & Stadelmann et al. (2007) \\
\hline TTU & 85090 & Myotis riparius & TK104318 & Ecuador & Pastaza & -1.46 & -78.10 & Larsen et al. (2012a) \\
\hline TTU & 122454 & Myotis riparius & $J X 130448$ & Paraguay & Canindeyú & -23.98 & -55.36 & Larsen et al. (2012a) \\
\hline MVZ & 185999 & Myotis ruber & AF376867 & Brazil & Salesopolis & -22.16 & -48.75 & Ruedi and Mayer (2001) \\
\hline UAMI & 15305 & Myotis velifer & $J X 130589$ & México & Michoacán & ---- & ---- & Larsen et al. (2012a) \\
\hline UAMI & 15306 & Myotis velifer & JX130438 & México & Michoacán & ---- & --- & Larsen et al. (2012a) \\
\hline MVZ & 146766 & Myotis velifer & AF376870 & México & Michoacán & 27.06 & -109.01 & Stadelmann et al. (2007) \\
\hline UAMI & 15304 & Myotis velifer & JX130462 & México & Michoacán & --- & --- & Larsen et al. (2012a \\
\hline TTU & 110032 & Myotis velifer & JX130582 & México & Tamaulipas & 24.01 & -98.34 & Larsen et al. (2012a) \\
\hline TTU & 44818 & Myotis velifer & EU680299 & México & Tamaulipas & --- & --- & Parlos et al. (2008) Unpublished \\
\hline TTU & 43197 & Myotis velifer & AY460343 & USA & Oklahoma & --- & --- & Rodriguez and Ammerman (2004) \\
\hline $\mathrm{CS}-\mathrm{H}$ & TK 46327 & Myotis velifer & $J X 130592$ & México & Michoacán & --- & --- & Larsen et al. (2012a) \\
\hline TK & 48587 & Myotis velifer & EF222340 & USA & Texas & --- & ---- & Baird et al. (2008) \\
\hline TTU & 44816 & Myotis velifer & $J X 130478$ & México & Tamaulipas & --- & --- & Larsen et al. (2012a) \\
\hline TTU & 60983 & Myotis velifer & JX130477 & San Salvador & Santa Ana & --- & --- & Larsen et al. (2012a) \\
\hline TTU & 109261 & Myotis velifer & $J X 130468$ & USA & Texas & 29.50 & -103.43 & Larsen et al. (2012a) \\
\hline No voucher & ---- & Myotis vivesi & AJ504406 & México & Gulf of California & 28.52 & 113.02 & Stadelmann et al. (2004) \\
\hline
\end{tabular}




\begin{tabular}{|c|c|c|c|c|c|c|c|c|}
\hline MVZ & 155853 & Myotis yumanensis & AF376875 & USA & California & 38.04 & -122.80 & Stadelmann et al. (2007) \\
\hline CM & 77691 & Myotis cf. nigricans & JX130497 & Suriname & Marowijne & ---- & ---- & Larsen et al. (2012a) \\
\hline TTU & 47514 & Myotis sp. & JX130449 & México & Yucatán & ca.20.96 & ca. -89.59 & Larsen et al. (2012a) \\
\hline JAG & 286 & Myotis sp. & $J X 130525$ & México & Yucatán & ---- & ---- & Larsen et al. (2012a) \\
\hline TK & 13532 & Myotis sp. & AF376852 & México & Yucatán & --- & --- & Ruedi and Mayer (2001) \\
\hline CM & 55764 & Myotis sp. & JX130489 & México & Vera Cruz & ---- & --- & Larsen et al. (2012a) \\
\hline MVZ & 226977 & Myotis sp. & MW025270 & Guatemala & Alta Verapaz & 15.61 & -90.27 & This study \\
\hline $\mathrm{CM}$ & 77705 & Myotis sp & JX130505 & Suriname & Paramaribo & --- & --- & Larsen et al. (2012a) \\
\hline TTU & 61228 & Myotis sp & JX1304931 & Honduras & Valle & 13.30 & -87.49 & Larsen et al. (2012a) \\
\hline TTU & 102707 & Myotis sp & JX130471 & Ecuador & Oro & -3.87 & -80.09 & Larsen et al. (2012a) \\
\hline \multirow[t]{2}{*}{ TTU } & 46348 & Myotis sp & JX130481 & Perú & Huánuco & ---- & --- & Larsen et al. (2012a) \\
\hline & & & & Outgroups & & & & \\
\hline NMPPB & 916 & Myotis brandtii & AM261886 & Russia & N-W. Russia & --- & --- & Stadelmann et al. (2007) \\
\hline Mgf & ---- & Myotis gracilis & AB243030 & Japan & Hokkaido & ---- & ---- & Kawai et al. (2006) \\
\hline MgE & ---- & Myotis gracilis & AB243029 & Japan & Hokkaido & ---- & --- & Kawai et al. (2006) \\
\hline OCUMS & 5362 & Myotis gracilis & AB106605 & Japan & Hokkaido & ---- & ---- & Kawai et al. (2003) \\
\hline KK & 0005 & Myotis yanbarensis & AB106610 & Japan & Hokkaido & --- & ---- & Kawai et al. (2003) \\
\hline
\end{tabular}

Appendix 3. List of specimens used in cytochrome oxidase c subunit I analyses of Neotropical Myotis. Specimens details, localities, and Genbank accession numbers of sampled individuals of Neotropical Myotis. Field Museum of Natural History (FMNH); Museum of Vertebrate, Zoology, University of California Berkeley (MVZ); Museum of Southwestern Biology, The University of New Mexico (MSB); Museum of Texas Tech University (TTU and TK); Royal Ontario Museum (ROM); Zoological Museum of Moscow State University (ZMMU).

\begin{tabular}{|c|c|c|c|c|c|c|c|c|}
\hline Institution & $\begin{array}{l}\text { Cat. No./Sequence } \\
\text { Code }\end{array}$ & Species & GenBank & Country & Locality & Lat. & Long. & Source \\
\hline ROM & 120231 & Myotis albescens & HQ545684 & Suriname & Sipaliwini & 1.94 & -56.06 & Lim et al. (unpubl.) \\
\hline TTU & 85060 & Myotis armiensis sp. $\mathrm{n}$. & MW042013 & Ecuador & Tungurahua & -1.34 & -78.2 & This study \\
\hline MSB & 262788 & Myotis armiensis sp. $\mathrm{n}$. & MW042014 & Panamá & $\begin{array}{l}\text { Las Nubes Ranger Station, } \\
\text { Parque Internacional La Amistad }\end{array}$ & 8.89 & -82.61 & This study \\
\hline No voucher & Mke140204.2.VS & Myotis armiensis sp. $\mathrm{n}$. & KX814396 & Costa Rica & $\begin{array}{l}\text { Valle del Silencio, Parque Inter- } \\
\text { nacional La Amistad }\end{array}$ & 9.10 & -82.96 & Chaverri et al. (2016) \\
\hline No voucher & Mke140204.4.VS & Myotis armiensis sp. $\mathrm{n}$. & KX814397 & Costa Rica & $\begin{array}{l}\text { Valle del Silencio, Parque Inter- } \\
\text { nacional La Amistad }\end{array}$ & 9.10 & -82.96 & Chaverri et al. (2016) \\
\hline No voucher & Mke140204.5.VS & Myotis armiensis sp. $\mathrm{n}$. & KX814398 & Costa Rica & $\begin{array}{l}\text { Valle del Silencio, Parque Inter- } \\
\text { nacional La Amistad }\end{array}$ & 9.10 & -82.96 & Chaverri et al. (2016) \\
\hline No voucher & Mke140204.8.VS & Myotis armiensis sp. $\mathrm{n}$. & KX814399 & Costa Rica & $\begin{array}{l}\text { Valle del Silencio, Parque Inter- } \\
\text { nacional La Amistad }\end{array}$ & 9.10 & -82.96 & Chaverri et al. (2016) \\
\hline No voucher & Mke150126.1.VS & Myotis armiensis sp. $\mathrm{n}$. & KX814400 & Costa Rica & $\begin{array}{l}\text { Valle del Silencio, Parque Inter- } \\
\text { nacional La Amistad }\end{array}$ & 9.08 & -82.97 & Chaverri et al. (2016) \\
\hline No voucher & Mke150201.18.VS & Myotis armiensis sp. $\mathrm{n}$. & KX814403 & Costa Rica & $\begin{array}{l}\text { Valle del Silencio, Parque Inter- } \\
\text { nacional La Amistad }\end{array}$ & 9.11 & -82.96 & Chaverri et al. (2016) \\
\hline No voucher & Mke140128.1.VS & Myotis armiensis sp. $\mathrm{n}$. & KX814393 & Costa Rica & $\begin{array}{l}\text { Valle del Silencio, Parque Inter- } \\
\text { nacional La Amistad }\end{array}$ & 9.10 & -82.96 & Chaverri et al. (2016) \\
\hline No voucher & Mke150126.3.VS & Myotis armiensis sp. $\mathrm{n}$. & KX814401 & Costa Rica & $\begin{array}{l}\text { Valle del Silencio, Parque Inter- } \\
\text { nacional La Amistad }\end{array}$ & 9.08 & -82.97 & Chaverri et al. (2016) \\
\hline No voucher & Mke140129.1.VS & Myotis armiensis sp. $\mathrm{n}$. & KX814394 & Costa Rica & $\begin{array}{l}\text { Valle del Silencio, Parque Inter- } \\
\text { nacional La Amistad }\end{array}$ & 9.08 & -82.97 & Chaverri et al. (2016) \\
\hline No voucher & Mke140131.3.VS & Myotis armiensis sp. $\mathrm{n}$. & KX814395 & Costa Rica & $\begin{array}{l}\text { Valle del Silencio, Parque Inter- } \\
\text { nacional La Amistad }\end{array}$ & 9.11 & -82.96 & Chaverri et al. (2016) \\
\hline No voucher & Mke150126.9.VS & Myotis armiensis sp. $\mathrm{n}$. & KX814402 & Costa Rica & $\begin{array}{l}\text { Valle del Silencio, Parque Inter- } \\
\text { nacional La Amistad }\end{array}$ & 9.08 & -82.97 & Chaverri et al. (2016) \\
\hline ROM & 104302 & Myotis armiensis sp. $\mathrm{n}$. & JF447424 & Panamá & Chiriquí & 8.87 & -82.75 & Clare et al. (2011) \\
\hline ROM & 97827 & Myotis nigricans & JQ601557 & Guyana & Kuma River & 3.26 & -59.71 & Engstrom et al. (unpubl.) \\
\hline ROM & 106737 & Myotis nigricans & JQ601572 & Guyana & Essequibo River & 1.58 & -58.63 & Lim et al. (unpubl.) \\
\hline ROM & 106772 & Myotis nigricans & JQ601574 & Guyana & Gunn's Strip & 1.65 & -58.63 & Lim et al. (unpubl.) \\
\hline
\end{tabular}




\begin{tabular}{|c|c|c|c|c|c|c|c|c|}
\hline ROM & F43329 & Myotis nigricans & JQ601579 & Guyana & Paruima & 5.81 & -61.06 & Lim et al. (unpubl.) \\
\hline ROM & 105148 & Myotis nigricans & JQ601611 & Ecuador & Parque Nacional Yasuní & -0.63 & -76.45 & Engstrom et al. (unpubl.) \\
\hline ROM & 118840 & Myotis nigricans & JQ601620 & Ecuador & Orellana & -0.68 & -76.43 & Reid et al. (unpubl.) \\
\hline ROM & 114671 & Myotis nigricans & JQ601582 & Guyana & Mount Ayanganna & 5.33 & -53.91 & Lim et al. (unpubl.) \\
\hline ROM & 98018 & Myotis nigricans & EF080493 & Guyana & Potaro-Sirapurini & 4.38 & -58.37 & Clare et al. (2007) \\
\hline ROM & 117431 & Myotis nigricans & EU096808 & Suriname & Sipaliwini & 4.54 & -56.93 & Borisenko et al. (2008) \\
\hline No voucher & Mni150205.28.VS & Myotis nigricans & KX814404 & Costa Rica & $\begin{array}{l}\text { Valle del Silencio, Parque Inter- } \\
\text { nacional la Amistad }\end{array}$ & 9.13 & -82.95 & Chaverri et al. 2016 \\
\hline FMNH & 174938 & Myotis oxyotus & JN847707 & Perú & Cusco, La Esperanza & -13.17 & -71.60 & Taylor et al. (2011) \\
\hline MVZ & 174408 & $\begin{array}{l}\text { Myotis oxyotus } \\
\text { gardneri }\end{array}$ & MW042015 & Costa Rica & $\begin{array}{l}\text { Refugio Nacional Tapanti, } \\
\text { Cartago }\end{array}$ & 9.69 & -83.78 & This study \\
\hline No voucher & Mox140201.4.VS & $\begin{array}{l}\text { Myotis oxyotus } \\
\text { gardneri }\end{array}$ & KX814406 & Costa Rica & $\begin{array}{l}\text { Valle del Silencio, Parque Inter- } \\
\text { nacional La Amistad }\end{array}$ & 9.11 & -82.96 & Chaverri et al. (2016) \\
\hline No voucher & Mox140204.6.VS & $\begin{array}{l}\text { Myotis oxyotus } \\
\text { gardneri }\end{array}$ & KX814409 & Costa Rica & $\begin{array}{l}\text { Valle del Silencio, Parque Inter- } \\
\text { nacional La Amistad }\end{array}$ & 9.10 & -82.96 & Chaverri et al. (2016) \\
\hline No voucher & Mox140201.5.VS & $\begin{array}{l}\text { Myotis oxyotus } \\
\text { gardneri }\end{array}$ & KX814407 & Costa Rica & $\begin{array}{l}\text { Valle del Silencio, Parque Inter- } \\
\text { nacional La Amistad }\end{array}$ & 9.11 & -82.96 & Chaverri et al. (2016) \\
\hline No voucher & Mox140131.1.VS & $\begin{array}{l}\text { Myotis oxyotus } \\
\text { gardneri }\end{array}$ & KX814405 & Costa Rica & $\begin{array}{l}\text { Valle del Silencio, Parque Inter- } \\
\text { nacional La Amistad }\end{array}$ & 9.11 & -82.96 & Chaverri et al. (2016) \\
\hline No voucher & Mox140204.1.VS & $\begin{array}{l}\text { Myotis oxyotus } \\
\text { gardneri }\end{array}$ & KX814408 & Costa Rica & $\begin{array}{l}\text { Valle del Silencio, Parque Inter- } \\
\text { nacional La Amistad }\end{array}$ & 9.10 & -82.96 & Chaverri et al. (2016) \\
\hline No voucher & Mox150125.2.VS & $\begin{array}{l}\text { Myotis oxyotus } \\
\text { gardneri }\end{array}$ & KX814410 & Costa Rica & $\begin{array}{l}\text { Valle del Silencio, Parque Inter- } \\
\text { nacional La Amistad }\end{array}$ & 9.11 & -82.96 & Chaverri et al. (2016) \\
\hline No voucher & Mox150125.3.VS & $\begin{array}{l}\text { Myotis oxyotus } \\
\text { gardneri }\end{array}$ & KX814411 & Costa Rica & $\begin{array}{l}\text { Valle del Silencio, Parque Inter- } \\
\text { nacional La Amistad }\end{array}$ & 9.11 & -82.96 & Chaverri et al. (2016) \\
\hline No voucher & Mox150126.10.VS & $\begin{array}{l}\text { Myotis oxyotus } \\
\text { gardneri }\end{array}$ & KX814412 & Costa Rica & $\begin{array}{l}\text { Valle del Silencio, Parque Inter- } \\
\text { nacional La Amistad }\end{array}$ & 9.11 & -82.96 & Chaverri et al. (2016) \\
\hline MVZ & 226976 & Myotis pilosatibialis & MW042012 & Guatemala & Alta Verapaz & 15.61 & -90.27 & This study \\
\hline TTU & 35360 & Myotis pilosatibialis & MW042011 & México & San Luis Potosí & ca. 22.00 & ca. -99.00 & This study \\
\hline ROM & 101352 & Myotis pilosatibialis & $J F 446523$ & El Salvador & Santa Ana & 14.42 & -89.37 & Clare et al. (2011) \\
\hline ROM & 101433 & Myotis pilosatibialis & JF446527 & El Salvador & Santa Ana & 14.42 & -89.37 & Clare et al. (2011) \\
\hline ROM & 101432 & Myotis pilosatibialis & JF446528 & El Salvador & Santa Ana & 14.42 & -89.37 & Clare et al. (2011) \\
\hline ROM & 101431 & Myotis pilosatibialis & JF446529 & El Salvador & Santa Ana & 14.42 & -89.37 & Clare et al. (2011) \\
\hline ROM & 101357 & Myotis pilosatibialis & JF446532 & El Salvador & Santa Ana & 14.42 & -89.37 & Clare et al. (2011) \\
\hline ROM & 101356 & Myotis pilosatibialis & JF446533 & El Salvador & Sant Ana & 14.42 & -89.37 & Clare et al. (2011) \\
\hline ROM & 101355 & Myotis pilosatibialis & JF446535 & El Salvador & Sant Ana & 14.42 & -89.37 & Clare et al. (2011) \\
\hline ROM & 101354 & Myotis pilosatibialis & JF446536 & El Salvador & Sant Ana & 14.42 & -89.37 & Clare et al. (2011) \\
\hline ROM & 116560 & Myotis riparius & EF080496 & Guyana & Potaro-Siparuni & 5.25 & -59.61 & Clare et al. (2007) \\
\hline No voucher & AZ2407 & Myotis velifer & GU723140 & USA & Arizona & --- & --- & Streicker et al. (2010) \\
\hline ROM & 101358 & Myotis velifer & JF446538 & El Salvador & Santa Ana & 14.42 & -89.37 & Clare et al. (2011) \\
\hline No voucher & AZ4490 & Myotis yumanensis & GU723138 & USA & Arizona & --- & ---- & Streicker et al. (2010) \\
\hline No voucher & CA49 & Myotis yumanensis & GU723137 & USA & California & --- & --- & Streicker et al. (2010) \\
\hline TTU & 47514 & Myotis sp. & MW042010 & México & Yucatán & ca. 20.96 & ca. -89.59 & This study \\
\hline ROM & 99232 & Myotis sp. & JF446808 & Guatemala & Petén & 16.30 & -89.33 & Clare et al. (2011) \\
\hline ROM & 99233 & Myotis sp. & $J F 446809$ & Guatemala & Petén & 16.30 & -89.33 & Clare et al. (2011) \\
\hline ROM & 96463 & Myotis sp. & $J F 447270$ & México & Yucatán, Loltun & 20.25 & -89.48 & Clare et al. (2011) \\
\hline ROM & FN33842 & Myotis sp. & JF447274 & México & Quintana Roo, Tulum & ca. 20.21 & ca. -87.46 & Clare et al. (2011) \\
\hline \multirow[t]{2}{*}{ ROM } & FN33841 & Myotis sp. & $J F 447275$ & México & Quintana Roo, Tulum & ca. 20.21 & ca. -87.46 & Clare et al. (2011) \\
\hline & & & Outgroups & & & & & \\
\hline No voucher & Isolate IN 90 & Myotis lucifugus & GU723128 & USA & Indiana & --- & --- & Streicker et al. (2010) \\
\hline KZM & SVN 14-08 & Myotis brandtii & $J F 4429261$ & Russia & Sakhalin Region & --- & --- & Kruskop et al. (unpubl.) \\
\hline ZMMU & SVK 71-08_1 & Myotis brandtii & $J F 4429271$ & Russia & Republic of Gorno-Altay & 51.28 & 84.73 & Kruskop et al. (unpubl. \\
\hline ZMMU & SVK 71-08_2 & Myotis brandtii & $J F 4429281$ & Russia & Republic of Gorno-Altay & 51.28 & 84.73 & Kruskop et al. (unpubl.) \\
\hline ZMMU & S-171531 & Myotis brandtii & $J F 4429291$ & Russia & Kirov Region & 57.35 & 49.09 & Kruskop et al. (unpubl.) \\
\hline
\end{tabular}


Appendix 4. List of taxonomic samples included in nuclear gene analyses of Neotropical Myotis with institution, catalog number, species, locality and GenBank accession numbers: American Museum of Natural History (AMNH); Carnegie Museum of Natural History (CM); Field Museum of Natural History (FMNH); Indiana State University Collection (ISUV); Museum of Southwestern Biology, The University of New Mexico (MSB); Museo de Zoología de la Pontificia Universidad Católica del Ecuador (QCAZ); Museum of Texas Tech University (TTU and TK); Universidad Autónoma Metropolitana-Iztapalapa (UAMI).

\begin{tabular}{|c|c|c|c|c|c|c|c|}
\hline Institution & Cat. No. & Species & Locality & RAG2 & PRKC1 & STAT5A & THY \\
\hline $\mathrm{CM}$ & 77691 & Myotis albescens & Suriname, Marowijne & GU328076 & GU328317 & GU328390 & GU328460 \\
\hline AMNH & 261790 & Myotis albescens & Bolivia, Beni & MW042018 & MW041998 & MW041984 & MW041970 \\
\hline MSB & 262085 & Myotis armiensis sp. $\mathrm{n}$. & Chiriquí, Panama & MW042027 & MW042008 & MW041994 & MW041980 \\
\hline QCAZ & 17245 & Myotis armiensis sp. $\mathrm{n}$. & Napo, Ecuador & (not sequenced) & MW042005 & MW041991 & MW041977 \\
\hline MSB & 75643 & Myotis auriculus & New Mexico, USA & MW042019 & MW041999 & MW041985 & MW041971 \\
\hline TK & 79325 & Myotis californicus & USA, Texas & GU328078 & GU328319 & GU328392 & GU328462 \\
\hline TK & 83155 & Myotis ciliolabrum & USA, Texas & GU328080 & GU328321 & GU328394 & GU328464 \\
\hline MSB & 43105 & Myotis ciliolabrum & Mexico, Baja California & MW042016 & MW041996 & MW041982 & MW041968 \\
\hline TTU & 31503 & Myotis dominicensis & $\begin{array}{l}\text { Dominica, St. Joseph Parish, } \\
\text { Dominica }\end{array}$ & GU328081 & GU328322 & GU328395 & GU328465 \\
\hline MSB & 279297 & Myotis evotis & USA, New Mexico & MW042020 & MW042000 & MW041986 & MW041972 \\
\hline UAMI-TK & 43186 & Myotis fortidens & Mexico, Michoacán & GU328082 & GU328323 & GU328396 & GU328466 \\
\hline TK & 13532 & Myotis sp. & Yucatán, México & GU328083 & GU328324 & GU328397 & GU328467 \\
\hline FMNH & 141600 & Myotis levis & Sao Paulo, Brazil & GU328085 & GU328326 & GU328399 & GU328469 \\
\hline MSB & 70384 & Myotis levis & Bolivia & MW042021 & MW042001 & MW041987 & MW041973 \\
\hline FMNH & 129210 & Myotis nigricans & Amazonas, Perú & GU328088 & GU328329 & GU328402 & GU328472 \\
\hline AMNH & 268591 & Myotis riparius & Paracou, French Guiana & GU328089 & GU328330 & GU328403 & GU328473 \\
\hline AMNH & 268649 & Myotis riparius & Bolivia, Cochabamba & MW042022 & MW042002 & MW041988 & MW041974 \\
\hline AMNH & 261108 & Myotis riparius & Bolivia, Chuquisaca & MW042024 & MW042004 & MW041990 & MW041976 \\
\hline $\begin{array}{l}\text { ISUV } 6454 \\
\text {-DWS }\end{array}$ & 6454 & Myotis septentrionalis & USA, Indiana & GU328090 & GU328331 & GU328404 & GU328474 \\
\hline TTU & 79330 & Myotis thysanodes & USA, Texas & GU328091 & $\begin{array}{l}\text { (not se- } \\
\text { quenced) }\end{array}$ & $\begin{array}{l}\text { (not se- } \\
\text { quenced) }\end{array}$ & GU328475 \\
\hline TTU & 78599 & Myotis velifer & USA, Texas & AY141033 & GU328333 & GU328406 & GU328476 \\
\hline MSB & 53789 & Myotis velifer & Mexico, Sonora & MW042023 & MW042003 & MW041989 & MW041975 \\
\hline TTU & 79545 & Myotis volans & USA, Texas & GU328092 & GU328334 & GU328407 & GU328477 \\
\hline TTU & 43200 & Myotis yumanensis & USA, Oklahoma & GU328094 & GU328336 & GU328049 & GU328479 \\
\hline MSB & 42790 & Myotis sp. & Mexico, Baja California & MW042028 & MW042009 & MW041995 & MW041981 \\
\hline AMNH & 268651 & Myotis keaysi & Bolivia, Cochabamba & MW042025 & MW042006 & MW041992 & MW041978 \\
\hline \multirow[t]{2}{*}{ MSB } & 235490 & Myotis cf. nigricans & Bolivia, Tarija & MW042026 & MW042007 & MW041993 & MW041979 \\
\hline & & & & Outgroup & & & \\
\hline MSB & 94052 & Myotis cf. ikonnikovi & Mongolia, Ovorkhangai & MW042017 & MW041997 & MW041983 & MW041969 \\
\hline
\end{tabular}


Appendix 5. Post-hoc multiple comparison test with Bonferroni corrected approach.

\begin{tabular}{|c|c|c|c|c|c|c|c|c|c|}
\hline Factor & Group 1 & Grupo 2 & $\begin{array}{c}\text { Sample } \\
\text { size group } \\
1\end{array}$ & $\begin{array}{c}\text { Sample } \\
\text { size group } \\
2\end{array}$ & Statistics & df & $\mathbf{p}$ & p. adj & $\begin{array}{l}\text { p. adj. } \\
\text { signif }\end{array}$ \\
\hline PC1 & M. armiensis sp. $\mathrm{n}$. & M. sp. & 10 & 5 & 1.5093 & 12.9886 & 0.155 & 0.31 & ns \\
\hline PC1 & M. armiensis sp. $\mathrm{n}$. & M. o. gardneri & 10 & 6 & -5.1609 & 13.8910 & 0.000148 & 0.001 & ** \\
\hline PC1 & M. armiensis sp. n. & M. str. keaysi & 10 & 5 & -4.1027 & 10.1119 & 0.002 & 0.013 & * \\
\hline PC1 & M. armiensis sp. $\mathrm{n}$. & M. str. pilosatibialis & 10 & 8 & -1.9745 & 9.5891 & 0.078 & 0.233 & ns \\
\hline PC1 & M. sp. & M. o.gardneri & 5 & 6 & -8.5816 & 8.9647 & $1.29 \mathrm{E}-05$ & 0.000129 & *** \\
\hline PC1 & M. sp. & M. str. keaysi & 5 & 5 & -6.1634 & 6.4085 & 0.000651 & 0.005 & ** \\
\hline PC1 & M. sp. & M. str. pilosatibialis & 5 & 8 & -5.6729 & 4.6410 & 0.003 & 0.015 & * \\
\hline PC1 & M. o. gardneri & M. str. keaysi & 6 & 5 & 0.0678 & 6.7613 & 0.948 & 0.948 & ns \\
\hline PC1 & M. o. gardneri & M. str. pilosatibialis & 6 & 8 & 6.0262 & 5.7218 & 0.001 & 0.008 & $* *$ \\
\hline PC1 & M. str. keaysi & M. str. pilosatibialis & 5 & 8 & 3.6629 & 4.2129 & 0.02 & 0.079 & ns \\
\hline PC2 & M. armiensis sp. $\mathrm{n}$. & M. sp. & 10 & 5 & 7.4576 & 10.0559 & $2.10 \mathrm{E}-05$ & 0.000189 & *** \\
\hline PC2 & M. armiensis sp. n. & M. o gardneri & 10 & 6 & 0.7331 & 13.5877 & 0.476 & 0.476 & ns \\
\hline PC2 & M. armiensis sp. n. & M. str. keaysi & 10 & 5 & 2.8433 & 11.4061 & 0.016 & 0.062 & ns \\
\hline PC2 & M. armiensis sp. $\mathrm{n}$. & M. str. pilosatibialis & 10 & 8 & 3.6824 & 10.5644 & 0.004 & 0.019 & * \\
\hline PC2 & M. sp. & M. o. gardneri & 5 & 6 & -10.3063 & 6.5480 & $2.76 \mathrm{E}-05$ & 0.000221 & $* * *$ \\
\hline PC2 & M. sp. & M. str. keaysi & 5 & 5 & -9.9125 & 6.7270 & $2.95 \mathrm{E}-05$ & 0.000221 & $* * *$ \\
\hline PC2 & M. sp. & M. str. pilosatibialis & 5 & 8 & -9.9022 & 10.9032 & $8.76 \mathrm{E}-07$ & 8.76E-06 & $* * * *$ \\
\hline PC2 & M. o. gardneri & M. str. keaysi & 6 & 5 & 3.0094 & 8.2366 & 0.016 & 0.062 & ns \\
\hline PC2 & M. o.gardneri & M. str. pilosatibialis & 6 & 8 & 4.3703 & 7.3463 & 0.003 & 0.018 & * \\
\hline PC2 & M. str. keaysi & M. str. pilosatibialis & 5 & 8 & 1.5858 & 8.3097 & 0.15 & 0.3 & ns \\
\hline
\end{tabular}


Appendix 6. Molecular synapomorphies of Myotis armiensis sp. $\mathrm{n}$, as revealed by maximum-parsimony (MP) analysis of cytochrome coxidase subunit I (657 bp). Molecular transformations were optimized on a $50 \%$ majority-rule consensus tree of the most parsimonious tree (576 steps; $[\mathrm{Cl}]=0.429$ ) resulting from the MP analysis of the cytochrome $c$ oxidase subunit I matrix. 17 fixed derived characters states were found in the newly identified lineage. Of these, 2 which are indicated by asterisks, have not evolved independently in any other species of New World Myotis. The remaining have appeared secondarily in at least one species of New World Myotis.

\begin{tabular}{lccr}
\hline & $\begin{array}{c}\text { Nucleotide position } \\
\text { /Codon position }\end{array}$ & $\begin{array}{c}\text { Character state in } \\
\text { M. armiensis sp. } \mathbf{n} .\end{array}$ & $\begin{array}{c}\text { Characters Con- } \\
\text { sistency } \text { Index }\end{array}$ \\
\hline 1 & $3 / 3$ & $\mathrm{~T}$ & 0.333 \\
2 & $93 / 3$ & $\mathrm{~A}$ & 0.222 \\
3 & $93 / 3$ & $\mathrm{~A}$ & 0.222 \\
4 & $102 / 3$ & $\mathrm{C}$ & 0.333 \\
5 & $162 / 3$ & $\mathrm{C}$ & 0.400 \\
6 & $180 / 3$ & $\mathrm{G}$ & 0.250 \\
7 & $264 / 3$ & $\mathrm{G}$ & 0.500 \\
8 & $366 / 3$ & $\mathrm{C}$ & 0.250 \\
9 & $375 / 3$ & $\mathrm{~T}$ & 0.200 \\
10 & $427 / 1$ & $\mathrm{C}$ & 0.333 \\
11 & $447 / 3$ & $\mathrm{C}$ & 0.500 \\
12 & $477 / 3$ & $\mathrm{G}$ & 0.500 \\
13 & $507 / 3$ & $\mathrm{C}$ & 0.250 \\
14 & $594 / 3$ & $\mathrm{C}$ & 0.333 \\
15 & $641 / 2^{*}$ & $\mathrm{~A}$ & 1.000 \\
16 & $646 / 1^{*}$ & $\mathrm{~A}$ & 1.000 \\
17 & $648 / 3$ & $\mathrm{G}$ & 0.250 \\
\hline
\end{tabular}

Appendix 7. Molecular synapomorphies of Myotis armiensis sp. n., as revealed by maximum-parsimony (MP) analysis of partial cytochrome $b$ ( $710 \mathrm{bp})$. Molecular transformations were optimized on a $50 \%$ majority-rule consensus tree of the most parsimonious tree (2846 steps; $[\mathrm{Cl}]=0.238$ ) resulting from the MP analysis of partial cytochrome $b .31$ fixed derived characters states were found in the newly identified lineage. Of these, 1 , which is indicated by asterisk, has not evolved independently in any other species of Neotropical Myotis. The remaining have appeared secondarily in at least one species of Neotropical Myotis.

\begin{tabular}{cccc}
\hline & $\begin{array}{l}\text { Nucleotide posi- } \\
\text { tion /Codon posi- } \\
\text { tion }\end{array}$ & $\begin{array}{l}\text { Character state in M. } \\
\text { armiensis sp. } \mathbf{n} .\end{array}$ & $\begin{array}{l}\text { Characters } \\
\text { Consistency } \\
\text { Index }\end{array}$ \\
\hline 1 & $120 / 3$ & $\mathrm{~T}$ & 0.167 \\
2 & $120 / 3$ & $\mathrm{C}$ & 0.167 \\
3 & $141 / 3$ & $\mathrm{G}$ & 0.333 \\
\hline
\end{tabular}

\begin{tabular}{|c|c|c|c|}
\hline 4 & $165 / 3$ & C & 0.053 \\
\hline 5 & $156 / 3$ & G & 0.250 \\
\hline 6 & $189 / 3$ & $\mathrm{~T}$ & 0.167 \\
\hline 7 & $315 / 3$ & A & 0.167 \\
\hline 8 & $336 / 3$ & $\mathrm{~T}$ & 0.333 \\
\hline 9 & $405 / 3$ & G & 0.125 \\
\hline 10 & $408 / 3$ & C & 0.214 \\
\hline 11 & $426 / 3$ & A & 0.111 \\
\hline 12 & $444 / 3$ & $\mathrm{~T}$ & 0.111 \\
\hline 13 & $471 / 3$ & C & 0.333 \\
\hline 14 & $507 / 3$ & C & 0.500 \\
\hline 15 & $513 / 3$ & C & 0.111 \\
\hline 16 & $537 / 3$ & C & 0.200 \\
\hline 17 & $570 / 3^{*}$ & G & 1.000 \\
\hline 18 & $603 / 3$ & $\mathrm{~T}$ & 0.167 \\
\hline 19 & $678 / 3$ & C & 0.167 \\
\hline 20 & $697 / 1$ & $\mathrm{~T}$ & 0.200 \\
\hline 21 & $723 / 3$ & C & 0.200 \\
\hline 22 & $741 / 3$ & C & 0.154 \\
\hline 23 & $744 / 3$ & $\mathrm{~T}$ & 0.143 \\
\hline 24 & $756 / 3$ & C & 0.077 \\
\hline 25 & $759 / 3$ & C & 0.125 \\
\hline 26 & $765 / 3$ & C & 0.100 \\
\hline 27 & $780 / 3$ & $C$ & 0.100 \\
\hline 28 & $798 / 3$ & C & 0.100 \\
\hline 29 & $804 / 3$ & C & 0.100 \\
\hline 30 & $813 / 3$ & G & 0.100 \\
\hline 31 & $822 / 3$ & $\mathrm{~T}$ & 0.143 \\
\hline
\end{tabular}

Appendix 8. Molecular synapomorphies of Myotis armiensis sp. $\mathrm{n}$., as revealed by maximum-parsimony (MP) analysis of protein kinase $C$, iota ( $\mathrm{PRKCl}, n=402 \mathrm{bp})$. Molecular transformations were optimized on a $50 \%$ majorityrule consensus tree of the most parsimonious tree (59 steps; $[\mathrm{Cl}]=0.966$ ) resulting from the MP analysis of protein kinase $C$, iota. All 4 fixed characters have not evolved independently in any other species of New World Myotis.

\begin{tabular}{lcccc}
\hline & \multicolumn{2}{c}{$\begin{array}{l}\text { ucleotide posi- } \\
\text { tion }\end{array}$} & $\begin{array}{l}\text { Character state in } \\
\text { M. armiensis sp. } \mathbf{n} .\end{array}$ & $\begin{array}{l}\text { Characters Consis- } \\
\text { tency Index }\end{array}$ \\
\hline 1 & 29 & $\mathrm{G}$ & 1.000 \\
2 & 51 & $\mathrm{C}$ & 1.000 \\
3 & 240 & $\mathrm{~T}$ & 1.000 \\
4 & 371 & $\mathrm{G}$ & 1.000 \\
\hline
\end{tabular}


Appendix 9. Molecular synapomorphies of Myotis armiensis sp. n., as revealed by maximum-parsimony (MP) analysis of signal transducer and activator of transcription 5A (STAT5A, $n=414 \mathrm{bp}$ ). Molecular transformations were optimized on a $50 \%$ majority-rule consensus tree of the most parsimonious tree (134 steps; $[\mathrm{Cl}]=0.754$ ) resulting from the MP analysis of signal transducer and activator of transcription 5A. 23 fixed derived characters states were found in the newly identified lineage. Of these, 9, which are indicated by asterisk, has not evolved independently in any other species of New World Myotis. The remaining have appeared secondarily in at least one species of New World Myotis.

\begin{tabular}{|c|c|c|c|}
\hline & $\begin{array}{l}\text { Nucleotide posi- } \\
\text { tion }\end{array}$ & $\begin{array}{l}\text { Character state in } \\
\text { M. armiensis sp. } n \text {. }\end{array}$ & $\begin{array}{l}\text { Characters Con- } \\
\text { sistency Index }\end{array}$ \\
\hline 1 & 10 & C & 0.500 \\
\hline 2 & 15 & $C$ & 0.500 \\
\hline 3 & $18^{*}$ & C & 1.000 \\
\hline 4 & $48^{*}$ & A & 1.000 \\
\hline 5 & 56 & $C$ & 0.500 \\
\hline 6 & 69 & C & 0.500 \\
\hline 7 & 72 & G & 0.667 \\
\hline 8 & 99* & C & 1.000 \\
\hline 9 & 145 & C & 0.333 \\
\hline 10 & 148 & C & 0.500 \\
\hline 11 & 154 & A & 0.333 \\
\hline 12 & 220 & C & 0.500 \\
\hline 13 & 254 & C & 0.500 \\
\hline 14 & $258 *$ & C & 1.000 \\
\hline 15 & $269 *$ & C & 1.000 \\
\hline 16 & 273 & A & 0.500 \\
\hline 17 & $276^{*}$ & C & 1.000 \\
\hline 18 & 355 & C & 0.500 \\
\hline 19 & 376 & C & 0.333 \\
\hline 20 & $391 *$ & $T$ & 1.000 \\
\hline 21 & $393 *$ & G & 1.000 \\
\hline 22 & 398 & G & 0.500 \\
\hline 23 & $405^{*}$ & G & 1.000 \\
\hline
\end{tabular}

Appendix 10. Molecular synapomorphies of Myotis armiensis sp. $\mathrm{n}$., as revealed by maximum-parsimony (MP) analysis of thyrotropin (THY, $n=475 \mathrm{bp}$ ). Molecular transformations were optimized on a $50 \%$ majority-rule consensus tree of the most parsimonious tree (138 steps; $[\mathrm{Cl}]=$ 0.906) resulting from the MP analysis of thyrotropin. 7 fixed derived characters states were found in the newly identified lineage. Of these, 6 , which are indicated by asterisk, have not evolved independently in any other species of New World Myotis. Only one has appeared secondarily in at least one species of New World Myotis.

\begin{tabular}{|c|c|c|c|}
\hline & $\begin{array}{l}\text { Nucleotide posi- } \\
\text { tion }\end{array}$ & $\begin{array}{l}\text { Character state in } \\
\text { M. armiensis sp. } n \text {. }\end{array}$ & $\begin{array}{l}\text { Characters Consis- } \\
\text { tency Index }\end{array}$ \\
\hline 1 & $161^{*}$ & G & 1.000 \\
\hline 3 & $220^{*}$ & G & 1.000 \\
\hline 2 & $235^{*}$ & G & 1.000 \\
\hline 4 & $277^{*}$ & $T$ & 1.000 \\
\hline 5 & $315^{*}$ & C & 1.000 \\
\hline 6 & $350 *$ & G & 1.000 \\
\hline 7 & 373 & C & 0.500 \\
\hline
\end{tabular}

